\title{
Hydration of the Bisulfate Ion: Atmospheric Implications
}

\author{
Devon E. Husar, Berhane Temelso, Alexa L. Ashworth, and George C. Shields* \\ Dean's Office, College of Arts and Sciences, and Department of Chemistry, Bucknell University, Lewisburg, Pennsylvania 17837, \\ United States
}

\section{Supporting Information}

ABSTRACT: Using molecular dynamics configurational sampling combined with ab initio energy calculations, we determined the low energy isomers of the bisulfate hydrates. We calculated the $\operatorname{CCSD}(\mathrm{T})$ complete basis set (CBS) binding electronic and Gibbs free energies for 53 low energy isomers of $\mathrm{HSO}_{4}^{-}\left(\mathrm{H}_{2} \mathrm{O}\right)_{n=1-6}$ and derived the thermodynamics of adding waters sequentially to the bisulfate ion and its hydrates. Comparing the $\mathrm{HSO}_{4}{ }^{-} / \mathrm{H}_{2} \mathrm{O}$ system to the neutral $\mathrm{H}_{2} \mathrm{SO}_{4} / \mathrm{H}_{2} \mathrm{O}$ cluster, water binds more strongly to the anion than it does to the neutral molecules. The difference in the binding thermodynamics of $\mathrm{HSO}_{4}{ }^{-} / \mathrm{H}_{2} \mathrm{O}$ and $\mathrm{H}_{2} \mathrm{SO}_{4} / \mathrm{H}_{2} \mathrm{O}$ systems decreases with increasing number of waters. The thermodynamics for the formation of $\mathrm{HSO}_{4}^{-}\left(\mathrm{H}_{2} \mathrm{O}\right)_{n=1-5}$ is favorable at $298.15 \mathrm{~K}$, and that of $\mathrm{HSO}_{4}{ }^{-}\left(\mathrm{H}_{2} \mathrm{O}\right)_{n=1-6}$ is favorable for $T<273.15 \mathrm{~K}$. The $\mathrm{HSO}_{4}{ }^{-}$ion is almost always hydrated at temperatures and relative humidity values encountered in the troposphere. Because the bisulfate ion binds more strongly to sulfuric acid than it does to water, it is expected to play a role in ion-induced nucleation by forming a strong complex with sulfuric acid and water, thus facilitating the formation of a critical nucleus.

\section{INTRODUCTION}

While tropospheric ions are not abundant compared to neutral species, they are thought to play an important role in the formation of secondary aerosols. Aerosols, particulates of either natural or anthropogenic source that are suspended in the atmosphere, form through complex nucleation processes that are not well understood. ${ }^{+}$The full role of aerosols in the global climate is not fully known, even though the consensus is that they have a net negative radiative forcing or cooling effect. ${ }^{2}$ Aerosols can scatter and absorb radiation; the direct scattering of incoming radiation causes atmospheric cooling, but absorption causes atmospheric warming. They can also grow to be cloud condensation nuclei (CCN) leading to increased cloud albedo, thus causing radiative cooling. Aerosols also affect the lifetime and precipitation efficiency of clouds. ${ }^{3}$ The particles in the atmosphere that act as CCNs are essential for cloud formation.

Secondary aerosol formation has been observed under all sorts of atmospheric conditions and in various geographic locations. $^{4-8}$ Sulfuric acid is at the core of this process as evidenced by the strong correlation between new particle formation (nucleation) rates and ambient sulfuric acid concentration. ${ }^{4-8}$ Sulfuric acid is produced in the atmosphere from the oxidation of sulfur dioxide by the hydroxyl radical. Various mechanisms have been proposed to explain how gasphase sulfuric acid leads to aerosol formation. ${ }^{9}$ Binary watersulfuric acid nucleation is expected to play a role in the cold free troposphere, and in combustion engines, and in volcanic and industrial plumes with dense $\mathrm{SO}_{2} / \mathrm{SO}_{3}$ concentrations. In the continental boundary layer, ternary water-sulfuric acid- ammonia nucleation ${ }^{10,11}$ is a likely mechanism, although the role of amines ${ }^{12-16}$ and volatile organic compounds ${ }^{17-19}$ is expected to be significant. Ion-induced nucleation has been implicated as another process that can contribute to new particle formation rates. ${ }^{20-26}$ Experimentally measured formation rates have been consistently higher than those predicted by the above mechanisms, suggesting that other processes may be important. ${ }^{27,28}$

In ion-induced nucleation (IIN), vapor species either directly cluster around an ion, or an ion plays a stabilizing role to keep condensing species from evaporating easily, or ion-ion recombination enables the formation of large clusters. The main source of ions or ions in the atmosphere is galactic cosmic rays (GCR), ${ }^{29,30}$ which constantly bombard and ionize vapor species, but radioactive decay of radon, lightning, and corona discharge contribute significantly in the lower troposphere. ${ }^{20,31}$ These ion pairs are lost to ion-ion recombination and scavenging by large aerosol particles. Because of the competition between the production and loss of ion pairs, the steady-state concentration of ions in the lower atmosphere is typically about $500-3000 \mathrm{~cm}^{-3}$, which is very small compared to the air density of $10^{19} \mathrm{~cm}^{-3}$ and typical gaseous sulfuric acid concentration of $10^{5}-10^{8} \mathrm{~cm}^{-3} \cdot 22,26,32,33$ Despite their limited concentration, the role of ions in new particle formation is a subject of great debate. In the middle and upper troposphere where the concentration of ion pairs is larger,

Received: January 20, 2012

Revised: April 10, 2012

Published: April 11, 2012 
temperatures are cooler, and $\mathrm{H}_{2} \mathrm{SO}_{4}$ concentration is lower, it is expected that IIN would play a bigger role. The controversy is mainly concerning the contribution of IIN in the lower troposphere. On one hand, the correlation between natural variations in GCRs and cloud cover hypothesized by Svensmark $^{29}$ suggests that ions play a central role in cloud formation. Many subsequent observations ${ }^{25}$ and models ${ }^{20,34-36}$ have concluded that almost all new particle formation is mediated by ions. On the contrary, the relationship between GCR fluctuation and global low-level cloud cover has been disputed in a series of studies. ${ }^{37,38}$ Observations and analyses have consistently claimed that IIN accounts for less than $15 \%$ of nucleation events in the lower troposphere. ${ }^{22,32,39-42}$ This debate has inspired the CLOUD (cosmics leaving outdoor droplets) experiment at CERN, the European Organization for Nuclear Research. ${ }^{30}$ The first results from that experiment conclude that ground level GCRs do increase aerosol formation, but the effect is not as significant as enhancement in new particle formation resulting from ternary nucleation involving ammonia and amines. ${ }^{43}$ Ground level GCRs increase nucleation 2 -fold at $292 \mathrm{~K}$ and more than 10-fold at 278 and $248 \mathrm{~K}$. In comparison, a typical atmospheric concentration of $100 \mathrm{ppt}$ (parts per trillion) of ammonia increases nucleation rates by a factor of $100-1000$ compared to binary $\mathrm{H}_{2} \mathrm{SO}_{4}-\mathrm{H}_{2} \mathrm{O}$ nucleation. $^{30}$

While the debate over the role of GCRs and IIN in aerosol formation continues, there is consensus about the preference of sulfuric acid to bind to negatively charged species. One of the most prevalent ions in the atmosphere is bisulfate $\left(\mathrm{HSO}_{4}{ }^{-}\right)$, and it is thought to play a central role in IIN. Understanding the hydration of the bisulfate ion is important for many reasons. First, many experimental determinations of the concentration of sulfuric acid rely on nitrate ion chemical ionization mass spectrometry (CIMS), which uses $\mathrm{NO}_{3}^{-} / \mathrm{HNO}_{3}$ to selectively ionize $\mathrm{H}_{2} \mathrm{SO}_{4}$ to $\mathrm{HSO}_{4}^{-}$for detection. ${ }^{44}$ Second, classical nucleation theory $(\mathrm{CNT})$, the theoretical framework for most new particle formation studies, approximates the thermodynamics of ion-water clustering using the Thomson equation, which relies on bulk dielectric constants, surface tension, and density to calculate free energies of hydration for small molecular clusters. ${ }^{39}$ As bulk properties are poor at describing clusters in the subnanometer range, the application of quantum mechanical methods is necessary to obtain reliable thermodynamics of small clusters. Several works on $\mathrm{HSO}_{4}{ }^{-}$and its hydrates have been reported. A study to find the experimental thermodynamic values for the $\mathrm{HSO}_{4}{ }^{-}\left(\mathrm{H}_{2} \mathrm{SO}_{4}\right)_{s<7}\left(\mathrm{H}_{2} \mathrm{O}\right)_{w<11}$ and $\left(\mathrm{H}^{+}\right)\left(\mathrm{H}_{2} \mathrm{SO}_{4}\right)_{s<5}\left(\mathrm{H}_{2} \mathrm{O}\right)_{w<16}$ system revealed that negative ions have a higher affinity for $\mathrm{H}_{2} \mathrm{SO}_{4}$ than do positive ions, thus demonstrating that negative ion nucleation with $\mathrm{H}_{2} \mathrm{SO}_{4} / \mathrm{H}_{2} \mathrm{O}$ is a more thermodynamically favorable path for aerosol growth than positive ion nucleation. ${ }^{45}$ The effect of ammonia on the gas-phase hydration of $\mathrm{HSO}_{4}{ }^{-}$was studied using PW91/6-311+ $+\mathrm{G}(3 \mathrm{df}, 3 \mathrm{pd})^{46}$ and second-order Møller-Plesset perturbation theory (MP2). ${ }^{47}$ Both methods concluded that the stabilizing effect of ammonia on neutral clusters does not extend to negatively charged particles. This is not surprising because $\mathrm{HSO}_{4}{ }^{-}$is a relatively weak acid so the base stabilization effect is lower compared to the neutral $\mathrm{H}_{2} \mathrm{SO}_{4}$. Therefore, the presence of $\mathrm{NH}_{3}$ is not expected to enhance the thermochemical stability of $\mathrm{HSO}_{4}{ }^{-}\left(\mathrm{H}_{2} \mathrm{O}\right)_{n \cdot}{ }^{46,47}$

Calculations by Kurtén et al. ${ }^{47}$ used MP2 with correction for higher-order electron correlation and anharmonicity to determine the thermodynamics of a few isomers of
$\mathrm{H}_{2} \mathrm{SO}_{4}\left(\mathrm{H}_{2} \mathrm{O}\right)_{n=1-4}$ and $\mathrm{HSO}_{4}^{-}\left(\mathrm{H}_{2} \mathrm{O}\right)_{n=1-4}$. The $\mathrm{HSO}_{4}{ }^{-}\left(\mathrm{H}_{2} \mathrm{O}\right)_{n=1-4}$ moieties were more strongly bound than neutral $\mathrm{H}_{2} \mathrm{SO}_{4}\left(\mathrm{H}_{2} \mathrm{O}\right)_{n=1-4}$ species, and they formed hydrates more readily. They also found that water monomers are more tightly bound to $\mathrm{HSO}_{4}^{-}$than to $\mathrm{H}_{2} \mathrm{SO}_{4}$, but this effect diminishes as the cluster grows in size. Their binding enthalpies and free energies agree moderately with experimental values by Blades et al. ${ }^{48}$ and Froyd and Lovejoy. ${ }^{45}$ Likewise, Nadykto's ${ }^{49}$ PW91/6-311++G(3df,3pd) thermodynamic values for $\mathrm{HSO}_{4}{ }^{-}\left(\mathrm{H}_{2} \mathrm{O}\right)_{n=1-5}$ only agree moderately with Froyd and Lovejoy's experimental values. ${ }^{45}$ The authors attribute the differences to the unjustified application of the linearized form of the van't Hoff relation to derive reaction enthalpies and entropies in the experimental work. We improve on the abovementioned references by: (1) using a molecular dynamics configurational sampling to search for more low energy isomers; (2) using a more rigorous basis set extrapolation; (3) including higher-order correlation corrections via coupled cluster singles doubles and perturbative triples $[\operatorname{CCSD}(\mathrm{T})]$; and (4) taking Boltzmann averages of isomers to account for the presence of thermally accessible isomers.

In the current study, we searched for the low energy structures of hydrogen sulfate hydrates $\mathrm{HSO}_{4}{ }^{-}\left(\mathrm{H}_{2} \mathrm{O}\right)_{n=1-6}$ using a combination of molecular dynamics sampling and $\mathrm{ab}$ initio calculations. We determined the thermodynamic properties of these different clusters and isolated the global and lowlying local minima. A Boltzmann averaged standard state enthalpy and free energy of formation of each cluster size allowed us to compare this system to the neutral sulfuric acid clusters. We then calculated the equilibrium concentrations of these hydrates in conditions typical of the lower troposphere and explored the implications on the formation of aerosols in the atmosphere. This work is a continuation of long-standing efforts to explore ion-molecule interactions, ${ }^{50-54}$ hydrogenbonded interactions, ${ }^{55-64}$ water cluster formation, ${ }^{55,56,65-73}$ and atmospheric processes. ${ }^{74-85}$

\section{METHODOLOGY}

For $\mathrm{HSO}_{4}{ }^{-}\left(\mathrm{H}_{2} \mathrm{O}\right)_{n=1-2}$, we used the three isomers reported by Kurtén and co-workers ${ }^{47}$ as our starting structures. For $\mathrm{HSO}_{4}{ }^{-}\left(\mathrm{H}_{2} \mathrm{O}\right)_{n=3-6}$, we ran molecular dynamics (MD) simulations and randomly sampled different configurations, which were subsequently optimized using MP2. Similar to our previous studies of water clusters, ${ }^{71,73}$ we ran a two-step gasphase MD simulation. First, the system was heated from $5 \mathrm{~K}$ to the final temperature $T_{\mathrm{f}}$ (typically $90-105 \mathrm{~K}$ ) over a period of $1 \mathrm{~ns}(\mathrm{~ns})$, and then the temperature remained at $T_{\mathrm{f}}$ for a $10 \mathrm{~ns}$ production run. All of the simulations used the TIP4P water model and the Generalized AMBER Force Field (GAFF). ${ }^{86}$ The nonbonded cutoff was set to $20 \AA$, and weighting factors of 2.0 and 1.2 for the nonbonded and electrostatic interactions were used. From these simulations, we extracted 200 configurations at regular intervals and used them as starting structures for geometry optimizations with the resolution-ofthe-identity MP2 (RI-MP2) method employing the aug-ccpVDZ basis set as implemented in ORCA. ${ }^{87}$ The configurations that converged to local minima were sorted by their electronic energies, and those within $7 \mathrm{kcal} \mathrm{mol}^{-1}$ of the global minimum were subject to vibrational frequency calculations using RIMP2/aug-cc-pVDZ and single point energy calculations with larger basis sets (RI-MP2/aug-cc-pVTZ, RI-MP2/aug-ccpVQZ). 
The RI-MP2 method ${ }^{88,89}$ with augmented correlationconsistent basis sets (aug-cc-pVNZ, denoted as aVNZ where $\mathrm{N}=\mathrm{D}, \mathrm{T}, \mathrm{Q}, 5)^{90-92}$ and corresponding auxiliary basis sets ${ }^{93}$ were used to obtain structures and binding energies. All of the configurations extracted from our MD simulations were fully optimized at the RI-MP2/aVDZ level using analytic gradients ${ }^{94}$ with strict convergence criteria. For $\mathrm{H}_{2} \mathrm{SO}_{4}\left(\mathrm{H}_{2} \mathrm{O}\right)_{n=1-2}$, we recently evaluated the sensitivity of binding energies to geometries computed using RI-MP2/aVDZ and RI-MP2/ aVTZ and concluded that it is very small. ${ }^{84}$ Also, including an extra d-function on sulfur, as is the case with the aug-cc$\mathrm{pV}(\mathrm{N}+\mathrm{d}) \mathrm{Z}$ basis sets, ${ }^{95}$ has virtually no effect on the structures and binding energies of this system. ${ }^{84}$

As is well-known, accurate interaction energies of noncovalently bonded systems are difficult to calculate because of basis set incompleteness (BSIE) and basis set superposition errors (BSSE). ${ }^{96}$ The failure of Gaussian basis sets to properly describe the electronic Coulomb cusp leads to slow convergence of the self-consistent field (SCF) and correlation energy with increasing basis set size. One can address the two issues by extrapolating the energy to the CBS limit ${ }^{97}$ and employing counterpoise corrections (CP). ${ }^{98}$ The RI-MP2 complete basis set limit is estimated using two extrapolation schemes. The 4-5 inverse polynomial extrapolation ${ }^{99,100}$ has been used extensively for water clusters:

$$
E_{N}^{\mathrm{RI}-\mathrm{MP2}}=E_{\mathrm{CBS}}^{\mathrm{RI}-\mathrm{MP} 2}+\frac{b}{(N+1)^{4}}+\frac{c}{(N+1)^{5}}
$$

where $E_{N}^{\mathrm{RI}-\mathrm{MP} 2}$ is the RI-MP2/aVNZ//RI-MP2/aVDZ energy, $E_{\mathrm{CBS}}^{\mathrm{RI}-\mathrm{MP} 2}$ is the extrapolated RI-MP2/CBS energy, $N$ is the largest angular momentum number for the aVNZ basis set $(N=2,3,4$ for $\mathrm{N}=\mathrm{D}, \mathrm{T}, \mathrm{Q}$ respectively), and $b$ and $c$ are fitting parameters. ${ }^{99,100}$ The extrapolation of the SCF energy using an exponential function and the RI-MP2 correlation energy using an inverse cubic function has been advocated by Halkier et al. $^{101,102}$

$$
\begin{aligned}
& E_{\mathrm{CBS}}^{\mathrm{SCF}}=E_{N}^{\mathrm{SCF}}+B e^{-A N} \\
& E_{\mathrm{CBS}}^{\mathrm{corr}}=\frac{N^{3} E_{N}^{\mathrm{corr}}-(N-1)^{3} E_{N-1}^{\mathrm{corr}}}{N^{3}-(N-1)^{3}} \\
& E_{\mathrm{CBS}}^{\mathrm{RI}-\mathrm{MP} 2}=E_{\mathrm{CBS}}^{\mathrm{SCF}}+E_{\mathrm{CBS}}^{\mathrm{corr}}
\end{aligned}
$$

Here, $A$ and $B$ are fitting parameters, $E_{\mathrm{CBS}}^{\mathrm{SCF}}, E_{\mathrm{CBS}}^{\mathrm{corr}}$, and $E_{\mathrm{CBS}}^{\mathrm{RI}-\mathrm{MP} 2}$ are the complete basis set SCF, RI-MP2 correlation, and total energies. The complete basis set SCF energy is determined using the aug-cc-pVNZ $(\mathrm{N}=\mathrm{D}, \mathrm{T}, \mathrm{Q})$ basis sets, while the extrapolated correlation energy is derived from the aug-ccpVNZ $(\mathrm{N}=\mathrm{T}, \mathrm{Q})$ correlation energies. We evaluate the performance of the two extrapolation schemes by comparing them against benchmark explicitly correlated MP2-F12 ${ }^{103}$ results that are essentially at the basis set limit. ${ }^{104,105}$ In particular, we used the density fitted MP2-F12 (DF-MP2-F12 or RI-MP2-F12) method employing the 3C(FIX) ansatz ${ }^{106}$ implemented in Molpro. ${ }^{107}$ We chose the cc-pVQZ-F12 (VQZF12) orbital basis ${ }^{108}$ with the recommended aVQZ/MP2fit basis for the density fitting of the two-electron integrals and ccpVQZ/JKfit auxiliary basis for the resolution of the identity approximation of the many-electon integrals in F12 theory.

The importance of higher-order electron correlation past the MP2 level of theory has been examined by comparing the $\mathrm{CCSD}(\mathrm{T}) / \mathrm{aVDZ}$ and $\mathrm{MP} 2 / \mathrm{aVDZ}$ single point energies at the
RI-MP2/aVDZ optimized geometry. The higher-order electron correlation correction is defined as:

$$
\begin{aligned}
\delta_{\mathrm{MP} 2}^{\mathrm{CCSD}(\mathrm{T})}= & \Delta E_{\mathrm{CCSD}(\mathrm{T}) / \mathrm{aVDZ} / / \mathrm{RI}-\mathrm{MP} 2 / \mathrm{aVDZ}} \\
& -\Delta E_{\mathrm{MP} 2 / \mathrm{aVDZ} / / \mathrm{RI}-\mathrm{MP} 2 / \mathrm{aVDZ}}
\end{aligned}
$$

The basis set dependence of $\delta_{\mathrm{MP2}}^{\mathrm{CCS}(\mathrm{T})}$ is often assumed to be very small, but recent studies ${ }^{109,110}$ advise against using a small double- $\zeta$ basis especially for hydrogen bonded systems. Of the various double- $\zeta$ basis sets, the aVDZ performed most satisfactorily, and it is used to calculate the $\operatorname{CCSD}(\mathrm{T})$ correction here. Therefore, we approximated the $\operatorname{CCSD}(\mathrm{T}) /$ CBS binding energies as a sum of the RI-MP2/CBS binding energies and the higher-order electron correlation correction:

$$
\Delta E_{\mathrm{CBS}}^{\mathrm{CCSD}(\mathrm{T})}=\Delta E_{\mathrm{CBS}}^{\mathrm{RI}-\mathrm{MP} 2}+\delta_{\mathrm{MP} 2}^{\mathrm{CCSD}(\mathrm{T})}
$$

Thermodynamic corrections of the $\operatorname{CCSD}(\mathrm{T}) / \mathrm{CBS}$ electronic energes were included using frequencies and rotational constants calculated at the RI-MP2/aVDZ level. The three temperatures $(T=216.65,273.15$, and $298.15 \mathrm{~K})$ were chosen as temperatures relevant to the troposphere and room temperature. The zero-point corrected energies $[E(0)]$, standard state enthalpies $[H(T)]$, and standard state Gibbs free energies $[G(T)]$ were calculated from a canonical partition function assuming the usual framework of ideal gas, rigid rotor, and harmonic oscillator (RRHO) approximations. The method is accurate enough that for the water hexamer, we have been able to predict the three lowest lying isomers (prism, cage, and book) at low temperature, and we show that cyclic isomers dominate at temperatures higher than $200 \mathrm{~K}^{72,85,111}$ Because of the small energetic differences between the different isomers, we have reported the numbers to the second decimal place even though the error bars in our calculations are bound to be larger. To incorporate the presence of many low energy isomers at a given temperature, we have taken a Boltzmann average of the standard enthalpies and Gibbs free energies for each cluster size. The Boltzmann averaged free energies are combined with typical concentrations of the water vapor to estimate the abundance of bisulfate hydrates at equilibrium in the troposphere. Standard state conditions are $1 \mathrm{~atm}$ pressure and the stated temperature.

\section{RESULTS}

Figure 1 demonstrates the convergence of RI-MP2 binding energies toward the complete basis limit estimated by the RIMP2-F12/VQZ-F12 method. Compared to the benchmark RIMP2-F12/VQZ-F12 values, employing Halkier's extrapolation scheme (CBS[Conv(DTQ)]) gives binding energies that are still not fully converged, while the 4-5 inverse polynomial extrapolation (CBS[4-5poly(DTQ)]) reproduces the benchmark RI-MP2-F12/VQZ-F12 values almost exactly. The $\operatorname{CCSD}(\mathrm{T})$ correction to the RI-MP2/CBS binding energy is found to be significant in Figure 2. The 53 minima reported in this study for $\mathrm{HSO}_{4}{ }^{-}\left(\mathrm{H}_{2} \mathrm{O}\right)_{n=1-6}$ are shown in Figures 3-8. They are labeled A, B, C, etc., based on their structural similarity and sorted in order of increasing energy.

The CCSD(T)/CBS binding energies for all of the clusters in this study are shown in Tables $1-5$. (The interested reader can find RI-MP2/CBS analogues of Tables 1-5 in Table S3S7, Supporting Information.) The electronic energy $\left[E_{\mathrm{e}}\right]$ and the standard state Gibbs free energy $[G(298.15 \mathrm{~K})]$ global minima all correspond to different isomers for all clusters 


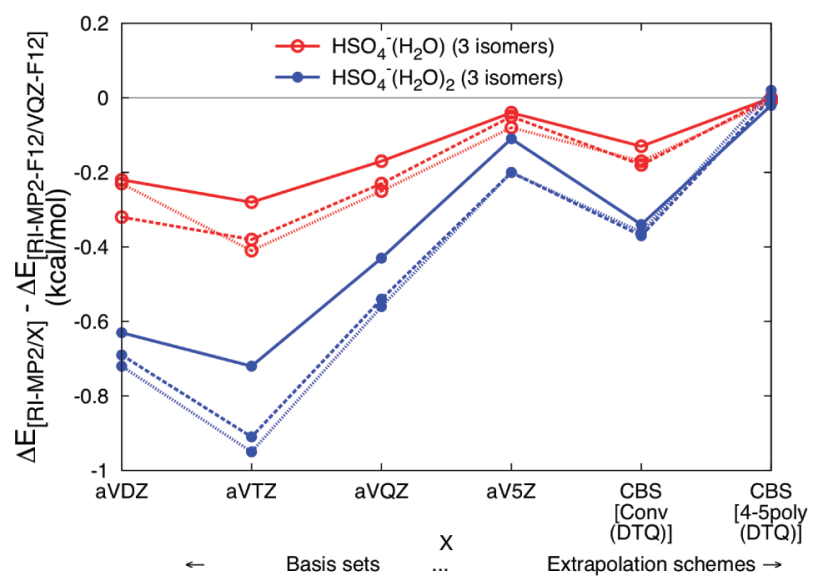

Figure 1. The difference between the RI-MP2/X and RI-MP2-F12/ VQZ-F12 binding energies for three isomers of $\mathrm{HSO}_{4}{ }^{-}\left(\mathrm{H}_{2} \mathrm{O}\right)_{n=1-2}$ where $\mathrm{X}$ is different basis sets and extrapolation procedures.

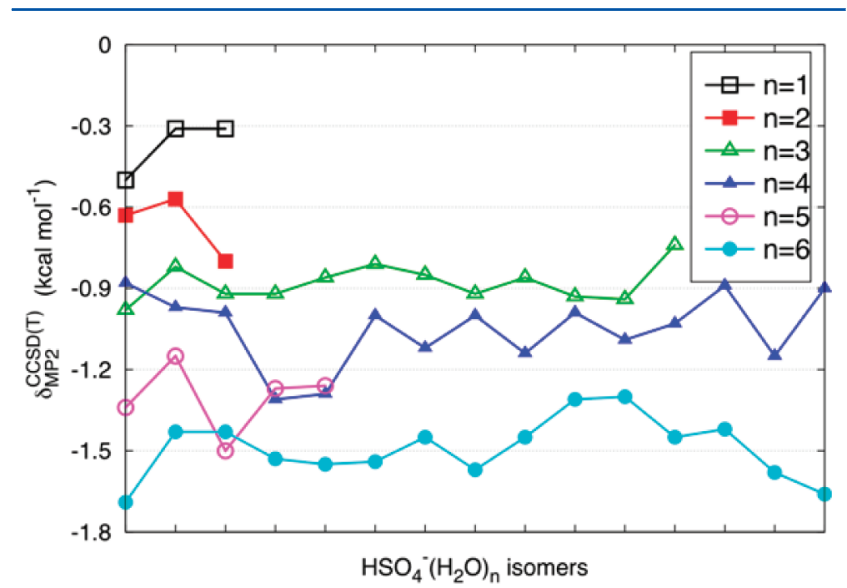

Figure 2. The $\operatorname{CCSD}(\mathrm{T})$ correction to the RI-MP2/CBS binding energy.

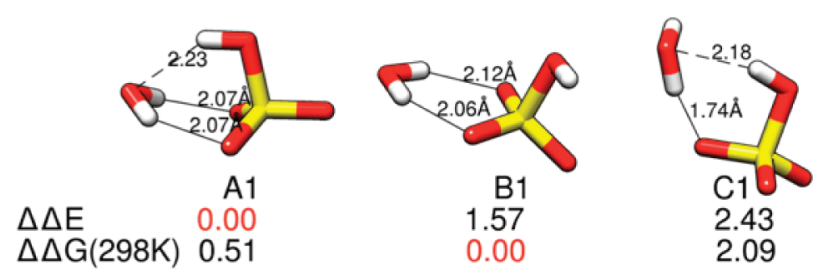

Figure 3. The $\mathrm{CCSD}(\mathrm{T}) / \mathrm{CBS}$ low energy isomers of $\mathrm{HSO}_{4}^{-}\left(\mathrm{H}_{2} \mathrm{O}\right)$ in $\mathrm{kcal} \mathrm{mol}^{-1}$.

except for $\mathrm{HSO}_{4}{ }^{-}\left(\mathrm{H}_{2} \mathrm{O}\right)_{5}$ and $\mathrm{HSO}_{4}^{-}\left(\mathrm{H}_{2} \mathrm{O}\right)_{6}$. The stability of the clusters depends on the number and type of hydrogen bonds. The following structural trends are notable. First, water-water hydrogen bonds are present for $n>1$. In cases

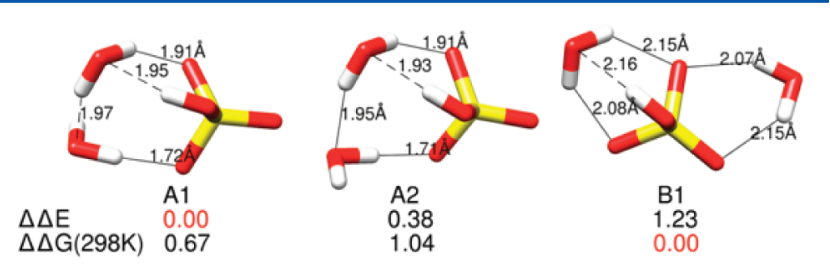

Figure 4. The $\operatorname{CCSD}(\mathrm{T}) / \mathrm{CBS}$ low energy isomers of $\mathrm{HSO}_{4}{ }^{-}\left(\mathrm{H}_{2} \mathrm{O}\right)_{2}$ in $\mathrm{kcal} \mathrm{mol}^{-1}$.

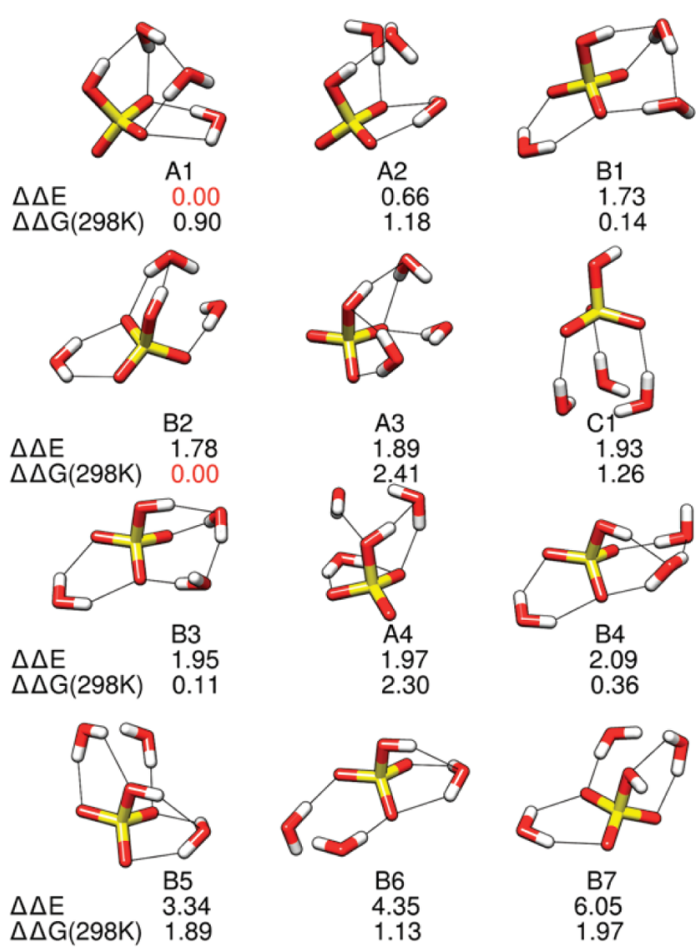

Figure 5. The $\operatorname{CCSD}(\mathrm{T}) / \mathrm{CBS}$ low energy isomers of $\mathrm{HSO}_{4}{ }^{-}\left(\mathrm{H}_{2} \mathrm{O}\right)_{3}$ in $\mathrm{kcal} \mathrm{mol}^{-1}$.

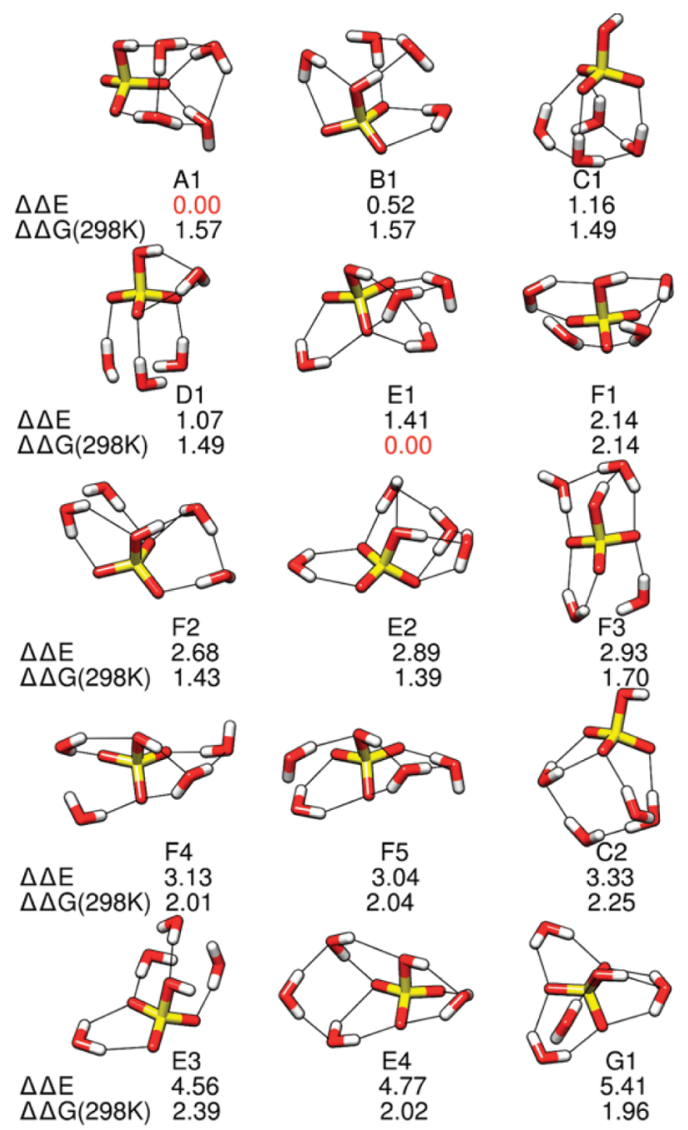

Figure 6. The $\operatorname{CCSD}(\mathrm{T}) / \mathrm{CBS}$ low energy isomers of $\mathrm{HSO}_{4}^{-}\left(\mathrm{H}_{2} \mathrm{O}\right)_{4}$ in $\mathrm{kcal} \mathrm{mol}^{-1}$

where waters donate two hydrogen bonds to the bisulfate, the hydrogen bonds are weak and highly nonlinear, leading to 


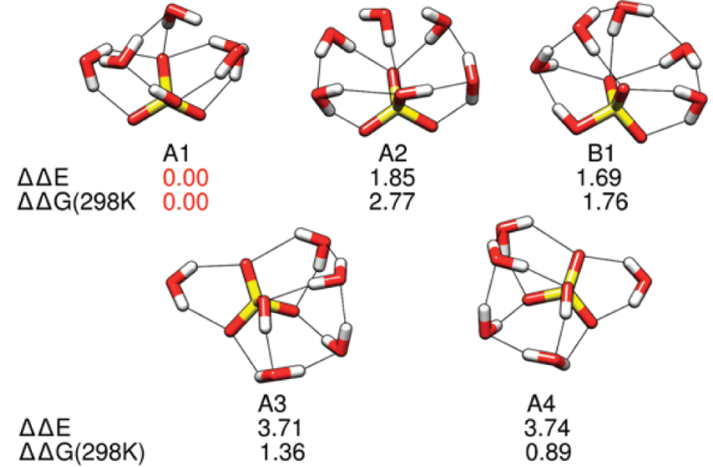

Figure 7. The $\mathrm{CCSD}(\mathrm{T}) / \mathrm{CBS}$ low energy isomers of $\mathrm{HSO}_{4}{ }^{-}\left(\mathrm{H}_{2} \mathrm{O}\right)_{5}$ in $\mathrm{kcal} \mathrm{mol}^{-1}$.

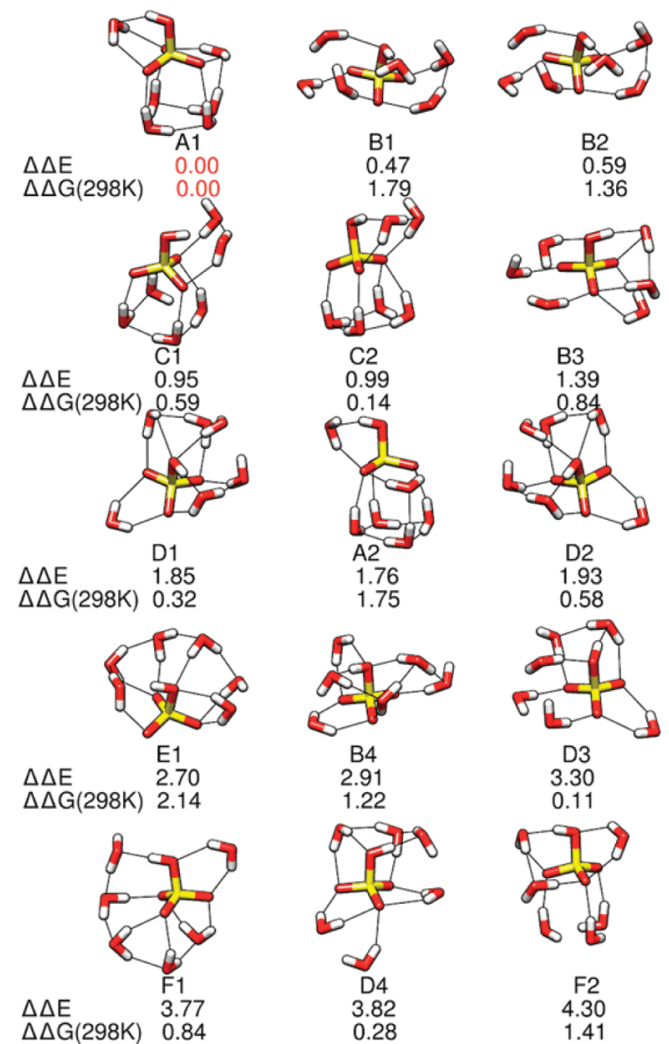

Figure 8. The $\mathrm{CCSD}(\mathrm{T}) / \mathrm{CBS}$ low energy isomers of $\mathrm{HSO}_{4}{ }^{-}\left(\mathrm{H}_{2} \mathrm{O}\right)_{6}$ in $\mathrm{kcal} \mathrm{mol}^{-1}$. structures that are not particularly favorable in enthalpic terms. Third, the acidic hydrogen of the bisulfate is almost always involved in hydrogen bonding. Increasing the number of waters leads to a fairly isotropic hydration of the bisulfate ion, even though a first hydration shell is far from complete.

The Boltzmann averaged CCSD $(\mathrm{T}) / \mathrm{CBS}$ binding energies are reported in Table 6 and graphed in Figure 9. The growth of $\mathrm{HSO}_{4}^{-}\left(\mathrm{H}_{2} \mathrm{O}\right)_{n=1-6}$ is thermodynamically favorable at $T=$ $216.65-273.15 \mathrm{~K}$ and $1 \mathrm{~atm}$, but only $n=1-5$ are likely to form at $T=298.15 \mathrm{~K}$. These results are not particularly different from those of $\mathrm{H}_{2} \mathrm{SO}_{4}\left(\mathrm{H}_{2} \mathrm{O}\right)_{n}$ where the formation of the hydrates is favorable for $n=1-6$ at $T=216.65-273.15 \mathrm{~K}$ and 1 atm, but only $n=1-4$ at higher temperatures. ${ }^{84}$ As shown in Figure S1, Supporting Information, the binding thermodynamics of $\mathrm{HSO}_{4}^{-}\left(\mathrm{H}_{2} \mathrm{O}\right)_{n}$ are significantly stronger than those of $\mathrm{H}_{2} \mathrm{SO}_{4}\left(\mathrm{H}_{2} \mathrm{O}\right)_{n}$ for $n=1-2$, but the difference is small for $n=3-4,6$ as the electrostatic effect of the ionic core weakens. The $\mathrm{HSO}_{4}{ }^{-}\left(\mathrm{H}_{2} \mathrm{O}\right)_{5}$ moiety appears to have unusual stability according to our calculations and from the results of an experimental quadruple time-of-flight mass spectroscopic (QTOF-MS) study by Zatula et al. ${ }^{112}$

A comparison of the calculated and experimental standard state enthalpy and Gibbs free energy at $298.15 \mathrm{~K}$ and $1 \mathrm{~atm}$ is shown in Figure 10. Froyd and Lovejoy ${ }^{45}$ determined the experimental $\Delta H$ and $\Delta S$ values from van't Hoff analysis of the change in hydration equilibrium constants as a function of temperature. Because of the error associated with the application of the linear van't Hoff equation, the $\Delta H$ values are not particularly reliable and the poor agreement between theory and experiment is not surprising. A direct comparison of the experimental $\Delta G$ with its calculated analogue is depicted in Figure 11 for $T=221 \mathrm{~K}$ and $T=271 \mathrm{~K}$. Here, theory predicts higher hydration Gibbs free energy than experiment, but the trends are similar.

To understand the implications of our study on the microhydration of $\mathrm{HSO}_{4}^{-}$and ion-induced nucleation, we calculated the equilibrium hydrate distribution of $\mathrm{HSO}_{4}{ }^{-}$at three tropospheric temperatures $(T=216.65,273.15$, and $298.15 \mathrm{~K})$ and relative humidity values $(\mathrm{RH}=20 \%, 50 \%$, and $100 \%)$. Figure 12 illustrates that virtually all $\mathrm{HSO}_{4}{ }^{-}$ions in the atmosphere are hydrated under the atmospheric conditions considered here. As expected, larger hydrates are favored at lower temperatures and higher $\mathrm{RH}$ values.

\section{DISCUSSION}

4.1. Basis Set Extrapolation Schemes. Figure 1 illustrates that the convergence of the binding energy to the CBS is not monotonic because of the incompleteness of the aVDZ basis

Table 1. $\mathrm{CCSD}(\mathrm{T}) / \mathrm{CBS}^{a}$ Harmonic Binding Energies for $\mathrm{HSO}_{4}{ }^{-}\left(\mathrm{H}_{2} \mathrm{O}\right)_{n=1-2}{ }^{b}$

\begin{tabular}{|c|c|c|c|c|c|c|c|c|c|}
\hline \multirow[b]{2}{*}{$n$} & \multirow[b]{2}{*}{ isomer } & \multirow{2}{*}{$\frac{\text { CBS }}{\Delta E_{\mathrm{e}}}$} & \multirow{2}{*}{$\frac{0 \mathrm{~K}}{\Delta E}$} & \multicolumn{2}{|c|}{$216.65 \mathrm{~K}$} & \multicolumn{2}{|c|}{$273.15 \mathrm{~K}$} & \multicolumn{2}{|c|}{$298.15 \mathrm{~K}$} \\
\hline & & & & $\Delta H$ & $\Delta G$ & $\Delta H$ & $\Delta G$ & $\Delta H$ & $\Delta G$ \\
\hline 1 & $\mathrm{~A} 1$ & -16.36 & -13.37 & -14.37 & -6.54 & -14.40 & -4.49 & -14.39 & -3.59 \\
\hline 1 & B1 & -14.79 & -12.63 & -13.25 & -6.59 & -13.18 & -4.86 & -13.14 & -4.10 \\
\hline 1 & $\mathrm{C} 1$ & -13.93 & -11.31 & -12.20 & -4.79 & -12.20 & -2.86 & -12.18 & -2.01 \\
\hline 2 & $\mathrm{Al}$ & -31.18 & -25.42 & -27.29 & -12.42 & -27.35 & -8.53 & -27.34 & -6.82 \\
\hline 2 & $\mathrm{~A} 2$ & -30.80 & -25.03 & -26.92 & -12.06 & -26.99 & -8.17 & -26.99 & -6.46 \\
\hline 2 & B1 & -29.95 & -24.97 & -26.46 & -12.66 & -26.40 & -9.07 & -26.34 & -7.50 \\
\hline
\end{tabular}

${ }^{a}$ Calculated as $\Delta E_{\mathrm{CBS}}^{\mathrm{CCSD}(\mathrm{T})}=\Delta E_{\mathrm{CBS}}^{\mathrm{R}-\mathrm{MP} 2}+\delta_{\mathrm{MP2}}^{\mathrm{CCSD}(\mathrm{T})}$. See text for details. ${ }^{b}$ All thermodynamic corrections calculated using RI-MP2/aVDZ geometries and vibrational frequencies. All energies are in $\mathrm{kcal} \mathrm{mol}^{-1}$. Global minima are shown in bold. Enthalpies and free energies are for a standard state of 1 atm. 
Table 2. $\mathrm{CCSD}(\mathrm{T}) / \mathrm{CBS}^{a}$ Harmonic Binding Energies for $\mathrm{HSO}_{4}{ }^{-}\left(\mathrm{H}_{2} \mathrm{O}\right)_{3}{ }^{b}$

\begin{tabular}{|c|c|c|c|c|c|c|c|c|c|}
\hline \multirow[b]{2}{*}{$n$} & \multirow[b]{2}{*}{ isomer } & \multirow[b]{2}{*}{$\Delta E_{\mathrm{e}}$} & \multirow{2}{*}{$\frac{0 \mathrm{~K}}{\Delta E}$} & \multicolumn{2}{|c|}{$216.65 \mathrm{~K}$} & \multicolumn{2}{|c|}{$273.15 \mathrm{~K}$} & \multicolumn{2}{|c|}{$298.15 \mathrm{~K}$} \\
\hline & & & & $\Delta H$ & $\overline{\Delta G}$ & $\overline{\Delta H}$ & $\Delta G$ & $\overline{\Delta H}$ & $\overline{\Delta G}$ \\
\hline 3 & Al & -45.78 & -37.17 & -39.90 & -17.59 & -39.97 & -11.76 & -39.95 & -9.20 \\
\hline 3 & $\mathrm{~A} 2$ & -45.12 & -36.75 & -39.43 & -17.26 & -39.49 & -11.46 & -39.47 & -8.91 \\
\hline 3 & B1 & -44.05 & -36.33 & -38.66 & -17.79 & -38.64 & -12.35 & -38.58 & -9.96 \\
\hline 3 & B2 & -44.00 & -36.33 & -38.64 & -17.89 & -38.61 & -12.47 & -38.55 & -10.10 \\
\hline 3 & A3 & -43.90 & -35.50 & -38.15 & -16.01 & -38.19 & -10.23 & -38.17 & -7.69 \\
\hline 3 & $\mathrm{C} 1$ & -43.85 & -35.75 & -38.16 & -16.84 & -38.17 & -11.28 & -38.12 & -8.84 \\
\hline 3 & B3 & -43.84 & -36.16 & -38.49 & -17.77 & -38.47 & -12.36 & -38.41 & -9.99 \\
\hline 3 & A4 & -43.82 & -35.42 & -38.03 & -16.06 & -38.07 & -10.32 & -38.03 & -7.80 \\
\hline 3 & B4 & -43.70 & -36.02 & -38.36 & -17.55 & -38.34 & -12.12 & -38.28 & -9.73 \\
\hline 3 & B5 & -42.45 & -34.84 & -37.09 & -16.09 & -37.03 & -10.61 & -36.95 & -8.21 \\
\hline 3 & B6 & -41.44 & -34.10 & -36.18 & -16.38 & -36.11 & -11.23 & -36.03 & -8.97 \\
\hline 3 & B7 & -39.74 & -33.14 & -34.95 & -15.42 & -34.77 & -10.34 & -34.65 & -8.12 \\
\hline
\end{tabular}

${ }^{a}$ Calculated as $\Delta E_{\mathrm{CBS}}^{\mathrm{CCSD}(\mathrm{T})}=\Delta E_{\mathrm{CBS}}^{\mathrm{R}-\mathrm{MP} 2}+\delta_{\mathrm{MP2}}^{\mathrm{CCSD}(\mathrm{T})}$. See text for details. ${ }^{b}$ All thermodynamic corrections calculated using RI-MP2/aVDZ geometries and vibrational frequencies. All energies are in $\mathrm{kcal} \mathrm{mol}^{-1}$. Global minima are shown in bold. Enthalpies and free energies are for a standard state of 1 atm.

Table 3. $\operatorname{CCSD}(\mathrm{T}) / \mathrm{CBS}^{a}$ Harmonic Binding Energies for $\mathrm{HSO}_{4}{ }^{-}\left(\mathrm{H}_{2} \mathrm{O}\right)_{4}{ }^{b}$

\begin{tabular}{|c|c|c|c|c|c|c|c|c|c|}
\hline \multirow[b]{2}{*}{$n$} & \multirow[b]{2}{*}{ isomer } & \multirow[b]{2}{*}{$\Delta E_{\mathrm{e}}$} & \multirow{2}{*}{$\frac{0 \mathrm{~K}}{\Delta E}$} & \multicolumn{2}{|c|}{$216.65 \mathrm{~K}$} & \multicolumn{2}{|c|}{$273.15 \mathrm{~K}$} & \multicolumn{2}{|c|}{$298.15 \mathrm{~K}$} \\
\hline & & & & $\Delta H$ & $\Delta G$ & $\Delta H$ & $\overline{\Delta G}$ & $\Delta H$ & $\Delta G$ \\
\hline 4 & A1 & -58.85 & -47.63 & -51.22 & -21.52 & -51.33 & -13.76 & -51.31 & -10.34 \\
\hline 4 & $\mathrm{~B} 1$ & -58.33 & -47.34 & -50.80 & -21.39 & -50.85 & -13.71 & -50.80 & -10.33 \\
\hline 4 & $\mathrm{C} 1$ & -57.69 & -46.65 & -49.92 & -21.21 & -49.96 & -13.71 & -49.91 & -10.41 \\
\hline 4 & D1 & -57.78 & -46.84 & -50.12 & -21.52 & -50.14 & -14.06 & -50.08 & -10.78 \\
\hline 4 & E1 & -57.44 & -47.14 & -50.17 & -22.35 & -50.13 & -15.09 & -50.06 & -11.91 \\
\hline 4 & $\mathrm{~F} 1$ & -56.71 & -46.04 & -49.31 & -20.56 & -49.31 & -13.06 & -49.24 & -9.76 \\
\hline 4 & $\mathrm{~F} 2$ & -56.17 & -45.89 & -48.97 & -20.98 & -48.93 & -13.69 & -48.85 & -10.48 \\
\hline 4 & E2 & -55.96 & -45.76 & -48.81 & -20.96 & -48.76 & -13.70 & -48.68 & -10.52 \\
\hline 4 & F3 & -55.92 & -45.67 & -48.75 & -20.73 & -48.72 & -13.42 & -48.64 & -10.21 \\
\hline 4 & F4 & -55.72 & -45.45 & -48.55 & -20.45 & -48.52 & -13.12 & -48.44 & -9.90 \\
\hline 4 & F5 & -55.81 & -45.46 & -48.56 & -20.43 & -48.52 & -13.09 & -48.45 & -9.87 \\
\hline 4 & $\mathrm{C} 2$ & -55.52 & -45.03 & -48.07 & -20.14 & -48.04 & -12.85 & -47.96 & -9.66 \\
\hline 4 & E3 & -54.29 & -44.31 & -47.17 & -19.78 & -47.07 & -12.65 & -46.97 & -9.52 \\
\hline 4 & E4 & -54.08 & -44.35 & -47.11 & -20.02 & -46.97 & -12.97 & -46.86 & -9.88 \\
\hline 4 & G1 & -53.44 & -44.05 & -46.66 & -19.94 & -46.49 & -12.99 & -46.35 & -9.95 \\
\hline
\end{tabular}

${ }^{a}$ Calculated as $\Delta E_{\mathrm{CBS}}^{\mathrm{CCSD}(\mathrm{T})}=\Delta E_{\mathrm{CBS}}^{\mathrm{R}-\mathrm{MP} 2}+\delta_{\mathrm{MP2}}^{\mathrm{CCSD}(\mathrm{T})}$. See text for details. ${ }^{b}$ All thermodynamic corrections calculated using RI-MP2/aVDZ geometries and vibrational frequencies. All energies are in $\mathrm{kcal} \mathrm{mol}^{-1}$. Global minima are shown in bold. Enthalpies and free energies are for a standard state of 1 atm.

Table 4. $\mathrm{CCSD}(\mathrm{T}) / \mathrm{CBS}^{a}$ Harmonic Binding Energies for $\mathrm{HSO}_{4}{ }^{-}\left(\mathrm{H}_{2} \mathrm{O}\right)_{5}{ }^{b}$

\begin{tabular}{|c|c|c|c|c|c|c|c|c|c|}
\hline \multirow[b]{2}{*}{$n$} & \multirow[b]{2}{*}{ isomer } & \multirow[b]{2}{*}{$\Delta E_{\mathrm{e}}$} & \multirow{2}{*}{$\frac{0 \mathrm{~K}}{\Delta E}$} & \multicolumn{2}{|c|}{$216.65 \mathrm{~K}$} & \multicolumn{2}{|c|}{$273.15 \mathrm{~K}$} & \multicolumn{2}{|c|}{$298.15 \mathrm{~K}$} \\
\hline & & & & $\Delta H$ & $\overline{\Delta G}$ & $\overline{\Delta H}$ & $\Delta G$ & $\Delta H$ & $\Delta G$ \\
\hline 5 & A1 & -73.27 & -59.44 & -63.67 & -27.45 & -63.75 & -17.99 & -63.70 & -13.83 \\
\hline 5 & $\mathrm{~A} 2$ & -71.42 & -57.45 & -61.81 & -24.93 & -61.89 & -15.30 & -61.85 & -11.07 \\
\hline 5 & $\mathrm{~B} 1$ & -71.58 & -57.92 & -62.09 & -25.74 & -62.13 & -16.24 & -62.06 & -12.07 \\
\hline 5 & A3 & -69.56 & -56.58 & -60.45 & -25.57 & -60.41 & -16.47 & -60.31 & -12.48 \\
\hline 5 & A4 & -69.53 & -56.65 & -60.47 & -25.91 & -60.43 & -16.90 & -60.33 & -12.94 \\
\hline
\end{tabular}

${ }^{a}$ Calculated as $\Delta E_{\mathrm{CBS}}^{\mathrm{CCSD}(\mathrm{T})}=\Delta E_{\mathrm{CBS}}^{\mathrm{RI}-\mathrm{MP} 2}+\delta_{\mathrm{MP2}}^{\mathrm{CCSD}(\mathrm{T})}$. See text for details. ${ }^{b}$ All thermodynamic corrections calculated using RI-MP2/aVDZ geometries and vibrational frequencies. All energies are in $\mathrm{kcal} \mathrm{mol}^{-1}$. Global minima are shown in bold. Enthalpies and free energies are for a standard state of 1 atm.

set and that the binding energy is not sufficiently converged even when using the large aV5Z basis set. Extrapolation schemes that rely only on the aVDZ and aVTZ basis sets ${ }^{47}$ will overestimate the binding because of the nonmonotonic convergence of the binding energies. The aVDZ basis alone might yield binding energies that are close to the true CBS values because of a fortuitous cancellation of errors resulting from BSSE and BSIE. We recently showed that the 4-5 inverse polynomial extrapolation (eq 1) scheme performs better than Halkier's conventional basis set extrapolation (eq 2) for water clusters $^{72}$ and sulfuric acid hydrates. ${ }^{84}$ By using RI-MP2-F12/ VQZ-F12 binding energies as a benchmark, we have evaluated the ability of the 4-5 inverse polynomial extrapolation scheme, designated as CBS[4-5poly(DTQ)], and Halkier's conven- 
Table 5. $\mathrm{CCSD}(\mathrm{T}) / \mathrm{CBS}^{a}$ Harmonic Binding Energies for $\mathrm{HSO}_{4}^{-}\left(\mathrm{H}_{2} \mathrm{O}\right)_{6}{ }^{b}$

\begin{tabular}{|c|c|c|c|c|c|c|c|c|c|}
\hline \multirow[b]{2}{*}{$n$} & \multirow[b]{2}{*}{ isomer } & \multirow{2}{*}{$\frac{\mathrm{CBS}}{\Delta E_{\mathrm{e}}}$} & \multirow{2}{*}{$\frac{0 \mathrm{~K}}{\Delta E}$} & \multicolumn{2}{|c|}{$216.65 \mathrm{~K}$} & \multicolumn{2}{|c|}{$273.15 \mathrm{~K}$} & \multicolumn{2}{|c|}{$298.15 \mathrm{~K}$} \\
\hline & & & & $\Delta H$ & $\Delta G$ & $\Delta H$ & $\Delta G$ & $\Delta H$ & $\Delta G$ \\
\hline 6 & A1 & -84.02 & -67.56 & -72.42 & -29.66 & -72.46 & -18.50 & -72.38 & -13.59 \\
\hline 6 & B1 & -83.55 & -67.15 & -72.29 & -28.33 & -72.38 & -16.85 & -72.32 & -11.80 \\
\hline 6 & B2 & -83.43 & -67.11 & -72.16 & -28.61 & -72.25 & -17.23 & -72.19 & -12.23 \\
\hline 6 & $\mathrm{C} 1$ & -83.07 & -66.94 & -71.79 & -29.06 & -71.84 & -17.91 & -71.76 & -13.00 \\
\hline 6 & $\mathrm{C} 2$ & -83.03 & -66.89 & -71.70 & -29.36 & -71.74 & -18.31 & -71.66 & -13.45 \\
\hline 6 & B3 & -82.63 & -66.65 & -71.43 & -28.78 & -71.44 & -17.65 & -71.35 & -12.76 \\
\hline 6 & D1 & -82.17 & -66.65 & -71.27 & -29.10 & -71.24 & -18.10 & -71.13 & -13.27 \\
\hline 6 & $\mathrm{~A} 2$ & -82.26 & -66.00 & -70.82 & -27.95 & -70.85 & -16.76 & -70.77 & -11.85 \\
\hline 6 & D2 & -82.09 & -66.54 & -71.21 & -28.89 & -71.17 & -17.86 & -71.06 & -13.01 \\
\hline 6 & E1 & -81.32 & -65.29 & -70.06 & -27.46 & -70.08 & -16.34 & -69.99 & -11.45 \\
\hline 6 & B4 & -81.11 & -65.78 & -70.36 & -28.20 & -70.32 & -17.20 & -70.21 & -12.37 \\
\hline 6 & D3 & -80.72 & -65.51 & -69.94 & -28.88 & -69.86 & -18.18 & -69.74 & -13.48 \\
\hline 6 & $\mathrm{~F} 1$ & -80.25 & -65.27 & -69.64 & -28.27 & -69.55 & -17.49 & -69.42 & -12.76 \\
\hline 6 & D4 & -80.20 & -65.44 & -69.72 & -28.69 & -69.59 & -18.00 & -69.45 & -13.32 \\
\hline 6 & $\mathrm{~F} 2$ & -79.72 & -64.58 & -68.95 & -27.67 & -68.85 & -16.91 & -68.72 & -12.18 \\
\hline
\end{tabular}

${ }^{a}$ Calculated as $\Delta E_{\mathrm{CBS}}^{\mathrm{CCSD}(\mathrm{T})}=\Delta E_{\mathrm{CBS}}^{\mathrm{RI} 2 \mathrm{MP}}+\delta_{\mathrm{MP2}}^{\mathrm{CCSD}(\mathrm{T})}$. See text for details. ${ }^{b}$ All thermodynamic corrections calculated using RI-MP2/aVDZ geometries and vibrational frequencies. All energies are in $\mathrm{kcal} \mathrm{mol}^{-1}$. Global minima are shown in bold. Enthalpies and free energies are for a standard state of 1 atm.

Table 6. $\mathrm{CCSD}(\mathrm{T}) / \mathrm{CBS}^{a}$ Boltzmann Averaged ${ }^{b}$ Harmonic Binding Energy of $\mathrm{HSO}_{4}{ }^{-}\left(\mathrm{H}_{2} \mathrm{O}\right)_{n} \mathrm{Hydrates}^{c}$

\begin{tabular}{|c|c|c|c|c|c|c|c|c|}
\hline \multirow[b]{2}{*}{$n$} & \multirow{2}{*}{$\frac{\mathrm{CBS}}{\Delta E[\mathrm{RI}-\mathrm{MP} 2]}$} & \multirow{2}{*}{$\frac{0 \mathrm{~K}}{\Delta E}$} & \multicolumn{2}{|c|}{$216.65 \mathrm{~K}$} & \multicolumn{2}{|c|}{$273.15 \mathrm{~K}$} & \multicolumn{2}{|c|}{$298.15 \mathrm{~K}$} \\
\hline & & & $\Delta H$ & $\Delta G$ & $\Delta H$ & $\Delta G$ & $\Delta H$ & $\Delta G$ \\
\hline \multicolumn{9}{|c|}{$\mathrm{HSO}_{4}^{-}+n\left(\mathrm{H}_{2} \mathrm{O}\right) \rightarrow \mathrm{HSO}_{4}^{-}\left(\mathrm{H}_{2} \mathrm{O}\right)_{n}$} \\
\hline 1 & -16.36 & -13.37 & -14.29 & -6.55 & -14.25 & -4.70 & -14.21 & -3.91 \\
\hline 2 & -31.18 & -25.42 & -27.11 & -12.51 & -27.14 & -8.83 & -27.12 & -7.23 \\
\hline 3 & -45.78 & -37.17 & -39.59 & -17.67 & -39.53 & -12.17 & -39.45 & -9.76 \\
\hline 4 & -58.85 & -47.63 & -50.94 & -21.93 & -50.92 & -14.47 & -50.84 & -11.20 \\
\hline 5 & -73.27 & -59.44 & -63.60 & -27.36 & -63.60 & -17.73 & -63.52 & -13.51 \\
\hline 6 & -84.02 & -67.56 & -72.13 & -29.22 & -72.12 & -18.07 & -72.02 & -13.22 \\
\hline \multicolumn{9}{|c|}{$\mathrm{HSO}_{4}^{-}\left(\mathrm{H}_{2} \mathrm{O}\right)_{n-1}+\mathrm{H}_{2} \mathrm{O} \rightarrow \mathrm{HSO}_{4}^{-}\left(\mathrm{H}_{2} \mathrm{O}\right)_{n}$} \\
\hline 1 & -16.36 & -13.37 & -14.29 & -6.55 & -14.25 & -4.70 & -14.21 & -3.91 \\
\hline 2 & -14.82 & -12.05 & -12.83 & -5.96 & -12.90 & -4.13 & -12.91 & -3.32 \\
\hline 3 & -14.60 & -11.75 & -12.47 & -5.17 & -12.38 & -3.34 & -12.32 & -2.53 \\
\hline 4 & -13.07 & -10.46 & -11.35 & -4.26 & -11.39 & -2.30 & -11.39 & -1.44 \\
\hline 5 & -14.42 & -11.80 & -12.67 & -5.43 & -12.69 & -3.26 & -12.68 & -2.31 \\
\hline 6 & -10.75 & -8.12 & -8.53 & -1.87 & -8.52 & -0.33 & -8.50 & 0.29 \\
\hline
\end{tabular}

${ }^{a}$ Calculated as $\Delta E_{\mathrm{CBS}}^{\mathrm{CCSD}(\mathrm{T})}=\Delta E_{\mathrm{CBS}}^{\mathrm{R}-\mathrm{MP} 2}+\delta_{\mathrm{MP2}}^{\mathrm{CCSD}(\mathrm{T})}$. See text for details. ${ }^{b} \Delta H(216.65 \mathrm{~K}), \Delta H(273.15 \mathrm{~K}), \Delta H(298.15 \mathrm{~K}), \Delta G(216.65 \mathrm{~K}), \Delta G(273.15$ $\mathrm{K})$, and $\Delta G(298.15 \mathrm{~K})$ Boltzmann averaged over low energy isomers. ${ }^{c}$ All thermodynamic corrections calculated using RI-MP2/aVDZ geometries and vibrational frequencies. All energies are in $\mathrm{kcal} \mathrm{mol}^{-1}$. Enthalpies and free energies are for a standard state of $1 \mathrm{~atm}$.

tional scheme, designated as $\mathrm{CBS}[\operatorname{Conv}(\mathrm{DTQ})]$, to lead to the CBS limit. CBS[Conv(DTQ)] actually performs worse than the aV5Z basis set, and using larger basis sets in the extrapolation, such as $\mathrm{CBS}[\mathrm{Conv}(\mathrm{TQ} 5)]$, did not necessarily lead to better binding energies, as shown in Table S1, Supporting Information. CBS[4-5poly(DTQ)] extrapolation reproduces the RI-MP2-F12/VQZ-F12 binding energies almost exactly. Our work shows that having a good basis set extrapolation method is essential. The difference in $\Delta E_{\mathrm{e}}$ between the two schemes is about $0.2 \mathrm{kcal} \mathrm{mol}^{-1}$ for $\mathrm{HSO}_{4}{ }^{-}\left(\mathrm{H}_{2} \mathrm{O}\right)$ and $0.4 \mathrm{kcal} \mathrm{mol}^{-1}$ for $\mathrm{HSO}_{4}{ }^{-}\left(\mathrm{H}_{2} \mathrm{O}\right)_{2}$, and it will presumably increase with the hydrate size. Errors of this magnitude will have dramatic effects on quantities like nucleation rates as they depend exponentially on the nucleation barriers.

4.2. Higher-Order Electron Correlation Correction. While $\operatorname{CCSD}(\mathrm{T})$ correction to the MP2 binding energy, $\delta_{\mathrm{MP2}}^{\mathrm{CCSD}(\mathrm{T})}$, for hydrogen-bonded systems is small, it is not negligible. Recent studies ${ }^{109,110,113}$ have warned against including this $\operatorname{CCSD}(\mathrm{T})$ correction to MP2 binding energies using small double- $\zeta$ basis. However, $\operatorname{CCSD}(\mathrm{T})$ single point calculations using larger basis are too expensive, thereby necessitating the use of a smaller basis. Of the double- $\zeta$ quality basis, the aVDZ basis performs best. ${ }^{109,110}$ The difference between the aVDZ and $\mathrm{aVTZ} \operatorname{CCSD}(\mathrm{T})$ correction for the three isomers of $\mathrm{HSO}_{4}{ }^{-}\left(\mathrm{H}_{2} \mathrm{O}\right)$ is less than $0.1 \mathrm{kcal}$ mol (see Table S2, Supporting Information). Because bisulfate is an anion, dispersion has a significant role in hydrogen bonding, and the $\operatorname{CCSD}(\mathrm{T})$ correction is expected to be larger than it would be for water clusters or neutral hydrates. Indeed, the correction to the RI-MP2/CBS binding energy is nonnegligible, ranging from about $-0.3 \mathrm{kcal} \mathrm{mol}^{-1}$ for $\mathrm{HSO}_{4}^{-}\left(\mathrm{H}_{2} \mathrm{O}\right)$ to about $-1.7 \mathrm{kcal} \mathrm{mol}{ }^{-1}$ for $\mathrm{HSO}_{4}{ }^{-}\left(\mathrm{H}_{2} \mathrm{O}\right)_{6}$, as illustrated in Figure 2. In contrast, the same correction never exceeds $0.5 \mathrm{kcal} \mathrm{mol}^{-1}$ for $\left(\mathrm{H}_{2} \mathrm{O}\right)_{n=2-10}{ }^{72}$ but can affect the energetic ordering of isomers. ${ }^{114}$ In our $\mathrm{H}_{2} \mathrm{SO}_{4}\left(\mathrm{H}_{2} \mathrm{O}\right)_{n}$ work, 

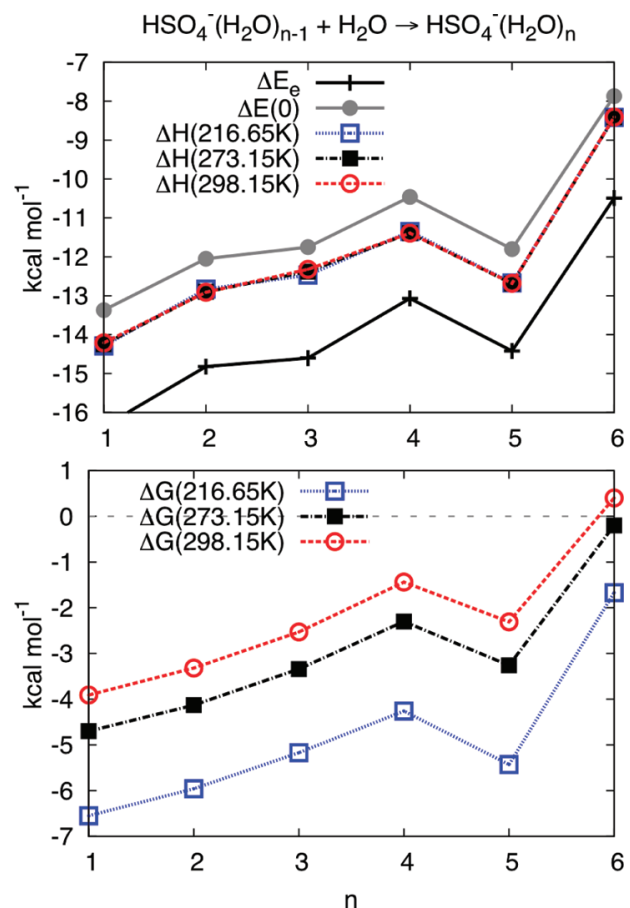

Figure 9. $\operatorname{CCSD}(\mathrm{T}) / \mathrm{CBS}$ Boltzmann averaged harmonic thermodynamics of stepwise bisulfate hydration.
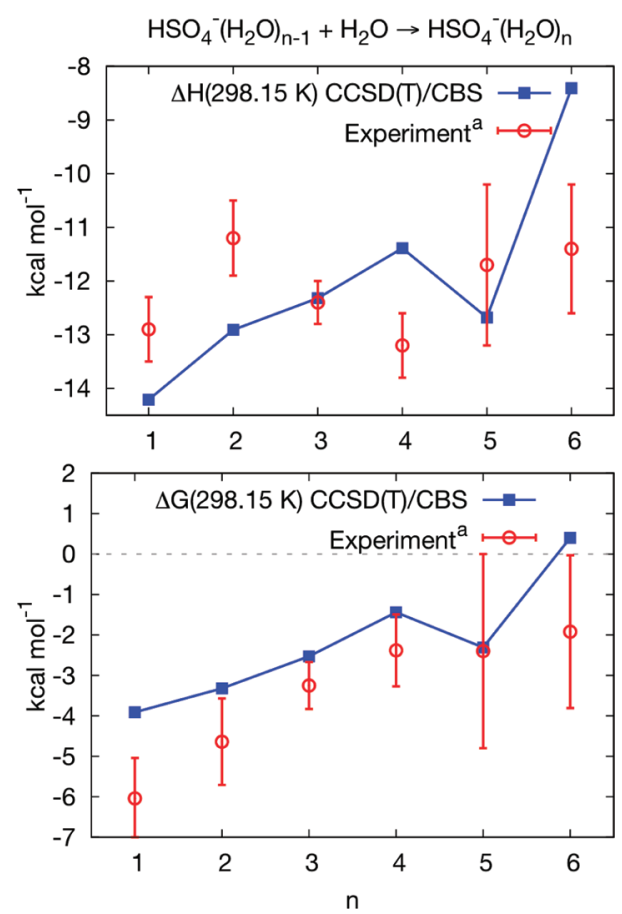

Figure 10. Comparison of the experimental and calculated $\operatorname{CCSD}(\mathrm{T}) /$ CBS $\Delta H(298.15 \mathrm{~K})$ (top) and $\Delta G(298.15 \mathrm{~K})$ (bottom) for the hydration of $\mathrm{HSO}_{4}^{-}$. The error bars in the experimental values represent the $95 \%$ confidence interval $(2 \sigma)$. (a) Reference 45 . Enthalpies and free energies are for a standard state of $1 \mathrm{~atm}$.

we opted not to include the $\operatorname{CCSD}(\mathrm{T})$ correction because it was typically small (between -0.2 and $+0.2 \mathrm{kcal} \mathrm{mol}^{-1}$ ) except for ionic pair $\left[\left(\mathrm{HSO}_{4}^{-} \cdot \mathrm{H}_{3} \mathrm{O}^{+}\right)\left(\mathrm{H}_{2} \mathrm{O}\right)_{n-1}\right]$ structures where it was larger. ${ }^{84}$ As a percentage of the RI-MP2/CBS electronic binding energy, $\delta_{\mathrm{MP2}}^{\mathrm{CCSD}(\mathrm{T})}$ for $\mathrm{HSO}_{4}{ }^{-}\left(\mathrm{H}_{2} \mathrm{O}\right)_{n=1-6}$ amounts to 2$3 \%$ in contrast to less than $1 \%$ for $\left(\mathrm{H}_{2} \mathrm{O}\right)_{n=2-10}$ and
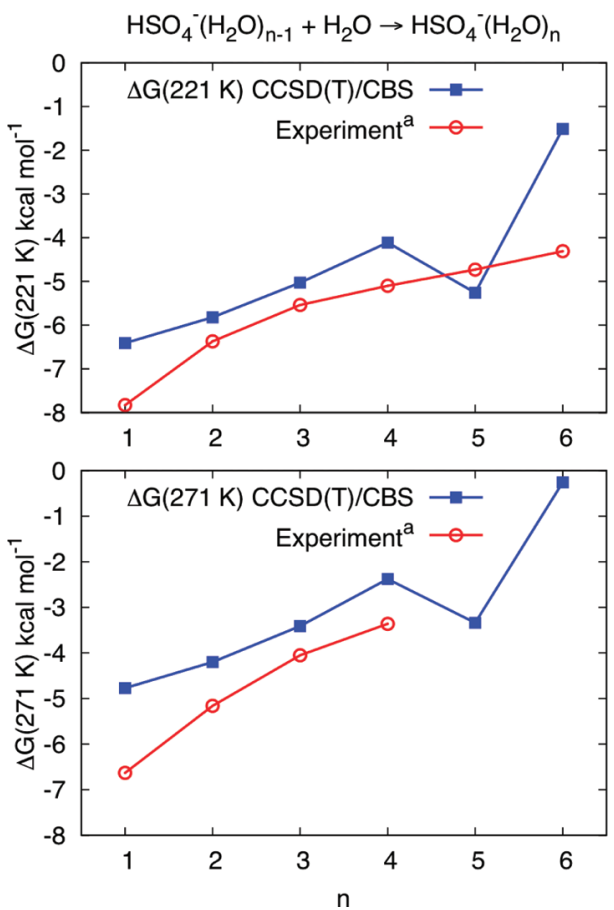

Figure 11. Comparison of the experimental and calculated $\operatorname{CCSD}(\mathrm{T}) /$ CBS $\Delta G(221 \mathrm{~K})$ (top) and $\Delta G(271 \mathrm{~K})$ (bottom) for the stepwise hydration of $\mathrm{HSO}_{4}^{-}$. (a) Reference 45. Enthalpies and free energies are for a standard state of $1 \mathrm{~atm}$.

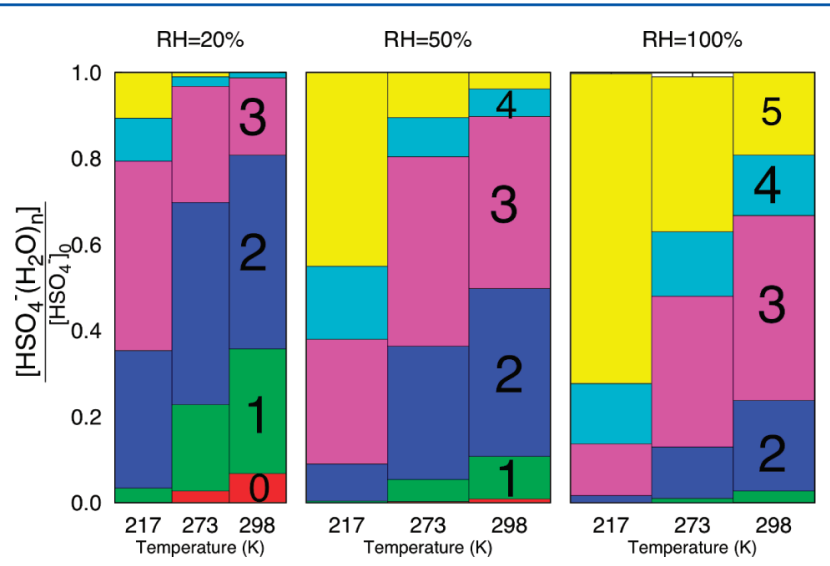

Figure 12. The equilibrium distribution of bisulfate hydrates assuming a saturation $(100 \% \mathrm{RH})$ vapor pressure of $\left[\mathrm{H}_{2} \mathrm{O}\right]=9.9 \times 10^{14}, 1.6 \times$ $10^{17}$, and $7.7 \times 10^{17} \mathrm{~cm}^{-3}$ at $T=216.65,273.15$, and $298.15 \mathrm{~K}$, respectively. The numbers inside the bar charts indicate $n$ in $\mathrm{HSO}_{4}{ }^{-}\left(\mathrm{H}_{2} \mathrm{O}\right)_{n}$. The hexahydrate, $\mathrm{HSO}_{4}{ }^{-}\left(\mathrm{H}_{2} \mathrm{O}\right)_{6}$, does not form in large enough numbers to be seen on this plot.

undissociated $\mathrm{H}_{2} \mathrm{SO}_{4}\left(\mathrm{H}_{2} \mathrm{O}\right)_{n}{ }^{72,84}$ The correction stabilizes all of the clusters by an average of about $0.3 \mathrm{kcal} \mathrm{mol}^{-1}$ per water.

4.3. Structures. The acidic proton of $\mathrm{HSO}_{4}{ }^{-}$can undergo free internal rotation at atmospheric temperatures because the barrier to the $\mathrm{H}-\mathrm{O}-\mathrm{S}=\mathrm{O}$ rotation is only $0.4 \mathrm{kcal} \mathrm{mol}^{-1}$ using MP2/6-311+G**. ${ }^{115}$ Furthermore, the flexible and dynamic nature of hydrogen bonds with water necessitates large configurational sampling to ensure that important structures are identified. Our MD configurational sampling and subsequent RI-MP2 calculations yielded the unique structures shown in Figures 3-8. To keep the size manageable, we only show those isomers whose relative electronic energy $(\Delta \Delta E)$ or 
standard state Gibbs free energy $[\Delta \Delta G(298.15 \mathrm{~K})]$ are within $2.5 \mathrm{kcal} \mathrm{mol}^{-1}$ of the global minimum isomer.

$\mathrm{Ab}$ initio quantum mechanical charge field molecular dynamics (QMCF MD) simulations predict that $\mathrm{HSO}_{4}^{-}$has a complex behavior where the solvation around the three equivalent oxygen sites is weak, but the acidic hydrogen always forms a strong hydrogen bond with water. ${ }^{116}$ Indeed, all of the global minima in our study show the hydrogen of $\mathrm{HSO}_{4}^{-}$ donating a hydrogen bond to a proximal water. Yacovitch et al.'s infrared multiple photon dissociation (IRMPD) spectroscopic study ${ }^{115}$ and MP2/6-311+G** calculations also identify increasing solvation around the acidic proton as a common feature of their most stable isomers. Besides the hydrogen bonding of the bisulfate acidic proton, another interesting structural feature is the presence of water-water hydrogen bonds for $n \geq 2$. Because the bisulfate ion has one hydrogen bond-donating and four hydrogen bond-accepting sites, the first few water monomers do not necessarily need to hydrogen bond with one another (see 2-B1 in Figure 4, for example), but they do because these water-water hydrogen bonds are less geometrically constrained. For example, the bridging double donor (DD) hydrogen-bonding motifs of water monomers, such as those of 1-A1, 1-B1, and 2-B1 isomers in Figures 3 and 4 , are weak due to the unfavorable hydrogen-bonding geometry; the typical hydrogen-bond distance and angle for this DD motif are about $2.0-2.2 \AA$ and $\sim 140^{\circ}$, respectively. Because these bridging DD hydrogen bonds are weak, they are entropically favorable. Indeed, all of the global $G(298.15 \mathrm{~K})$ minima (1-B1, 2-B1, 3-B2, 4-E1, 5-A1, and 6-A1) have at least one bridging $\mathrm{DD}$ water. The bridging $\mathrm{DD}$ motif is also the most common hydrogen bonding in the hydration of the sulfate dianion $\left(\mathrm{SO}_{4}{ }^{2-}\right)$ resulting from the stronger ion-water interaction. ${ }^{117^{4}}$

In Yacovitch et al.'s MP2/6-311+G** study, ${ }^{115}$ water rings start to form after the addition of the fourth water such that four water molecules make a tetramer ring that is bound to the bisulfate through three hydrogen bonds. ${ }^{115}$ All of their electronic energy global minima for $n=5-12$ exhibit this motif. The intensity of the peak corresponding to the $\mathrm{S}-\mathrm{O}-\mathrm{H}$ bending mode in their IRMPD spectra also decreases significantly for $n \geq 4$, suggesting that a water network is forming around the bisulfate hydrogen in a process that would eventually lead to acid dissociation. Our work paints a slightly different picture in that the waters are more evenly distributed around the whole ion instead of heavily wrapping around the acidic hydrogen. Part of this difference can be attributed to their use of electronic energies versus our use of both electronic and Gibbs free energies to pick out stable structures. In both their work and ours, the electronic energy $(E)$ global minima suggest that the bisulfate hydrogen is the focal point of the hydration. However, our $\mathrm{G}(298.15 \mathrm{~K})$ global minima point to a more isotropic hydration of the whole ion. Disproportionate hydration of the bisulfate hydrogen should lead to acid dissociation more quickly than a more uniform solvation. There is no indication of full acid dissociation of the bisulfate until the addition of at least 12 waters. None of our $\mathrm{HSO}_{4}{ }^{-}\left(\mathrm{H}_{2} \mathrm{O}\right)_{n}$ clusters deprotonated into $\mathrm{SO}_{4}{ }^{-2}\left(\mathrm{H}_{3} \mathrm{O}^{+}\right)$$\left(\mathrm{H}_{2} \mathrm{O}\right)_{n-1}$, a result in agreement with previous work. Zatula et al.'s QTOF MS experiments and B3LYP/6-311++G(2d,2p) study found no evidence of acid dissociation for small bisulfate hydrates. ${ }^{12}$ Sugawara et al. used path integral molecular dynamics (PIMD) simulations with modified PM6 parameters and predicted an onset of acid dissociation starting at $n=10-$
12. ${ }^{118}$ The first acid dissociation of sulfuric acid occurs after hydration with as little as four water molecules. ${ }^{84}$ In a bulk solution or small aerosols, it is expected that $\mathrm{H}_{2} \mathrm{SO}_{4}, \mathrm{HSO}_{4}{ }^{-}$, and the $\mathrm{SO}_{4}{ }^{2-}$ will all be present in equilibrium.

The electronic energy global minima reported here are similar but not identical to other MP2 works by Kurtén ${ }^{47}$ and Yacovitch. ${ }^{115}$ Nadykto's ${ }^{49}$ PW91/6-311++G(3df,3pd) and Zatula's $^{112}$ B3YLP/6-311+G(2d,2p) studies report different energetic orderings of the isomers. This is not surprising considering the failure of some density functionals to properly describe dispersion interactions inherent in hydrogen-bonded systems without empirical corrections. ${ }^{70,119,120}$

4.4. Thermodynamics of $\left(\mathrm{HSO}_{4}{ }^{-}\right)\left(\mathrm{H}_{2} \mathrm{O}\right)_{n}$ Formation. Holland and Castleman ${ }^{121}$ have shown that thermodynamics of ion-water clustering based on the classical Thomson equation, which relies on bulk properties, fare poorly in the small cluster limit. A proper description of small cluster thermodynamics warrants a rigorous quantum mechanical treatment. ${ }^{39}$ In this work, we have performed thorough configurational sampling to find the most likely stable isomers and applied MP2 theory to calculate accurate free energies for a standard state of $1 \mathrm{~atm}$ and relevant temperatures. In addition, we have taken a Boltzmann average of the ensemble of thermally accessible isomers to capture their contributions. The Boltzmann averaged thermodynamic values for the stepwise hydration of the bisulfate are given in Table 6 and plotted in Figure 9. This process takes into account the previous hydrate's thermodynamic properties and reveals how an additional water affects overall cluster equilibrium. For our system at $216.65-273.15 \mathrm{~K}$, the standard free energy is negative, implying that the formation of larger hydrates $(n=1-6)$ is thermodynamically favored. However, at 298.15 K, the Gibbs free energy turns positive for $n=6$ and will presumably remain positive for larger $n$. Therefore, hydrates with more than 5 waters are unlikely to form in significant quantities at $298.15 \mathrm{~K}$, as the energetic stabilization from forming new hydrogen bonds is not sufficient to overcome the entropic cost. Also, for a bisulfate with a full hydration shell, the charge on the ionic core is shielded from the approach of additional waters. As the cluster grows larger, the addition of each successive water results in weaker hydrogen bonds.

Our results qualitatively agree with Kurtén el al.'s study ${ }^{47}$ where they also employed the MP2 method but used aV(D $+\mathrm{d}) \mathrm{Z}$ and $\mathrm{aV}(\mathrm{T}+\mathrm{d}) \mathrm{Z}$ basis sets and an inverse cubic extrapolation (eq 2) instead of our 4-5 polynomial extrapolation (eq 1) scheme. Compared to the $298.15 \mathrm{~K}$ binding enthalpies $[\Delta H(298.15 \mathrm{~K})]$ and harmonic Gibbs free energies $[\Delta G(298.15 \mathrm{~K})]$ of their lowest energy isomers, ours are typically $1-2 \mathrm{kcal} \mathrm{mol}^{-1}$ higher for $\mathrm{HSO}_{4}{ }^{-}\left(\mathrm{H}_{2} \mathrm{O}\right)_{n=1-4}$. This difference can be attributed to the different energy extrapolation schemes (see section 4.1) and Kurtén's inclusion of MP4 higher-order electron correlation correction compared to $\operatorname{CCSD}(\mathrm{T})$ in our case (see section 4.2). The agreement with Nadykto's ${ }^{49}$ PW91/6-311++G(3df,3pd) thermodynamic values is also qualitative, with similar trends, but actual $\Delta H(298.15 \mathrm{~K})$ and $\Delta G(298.15 \mathrm{~K})$ values that differ by as much as $2 \mathrm{kcal}$ $\mathrm{mol}^{-1}$. The current work should be more robust than the aforementioned studies by virtue of inclusion of rigorous conformational sampling and more accurate energy calculations and extrapolations, but the discrepancies between the studies highlight the difficulty in calculating accurate thermodynamic quantities for hydrogen-bonded systems.

Experimental thermodynamic quantities for bisulfate hydrates have been determined by Froyd and Lovejoy ${ }^{45}$ who used 
an ion flow reactor coupled with a quadrupole mass spectrometer to obtain temperature-dependent equilibrium constants $\left(K_{\mathrm{eq}}\right)$ for formation of $\mathrm{HSO}_{4}{ }^{-}\left(\mathrm{H}_{2} \mathrm{SO}_{4}\right)_{s}\left(\mathrm{H}_{2} \mathrm{O}\right)_{w}$, where $s=0-6$ and $w=1-10$. For reactor temperatures of $T$ $=221,232,242,248,260$, and $271 \mathrm{~K}$, they provided stepwise $\Delta G(T)$ values for the $\mathrm{HSO}_{4}{ }^{-}\left(\mathrm{H}_{2} \mathrm{O}\right)_{w=1-6}$ system that we can compare to directly. Figure 11 shows a plot of their experimental and our calculated $\Delta G(221 \mathrm{~K})$ and $\Delta G(271 \mathrm{~K})$ values. The overall trend in the experimental and calculated stepwise $\Delta G(T)$ values is similar even though the calculated values are consistently $1-2 \mathrm{kcal} \mathrm{mol}^{-1}$ higher than the experimental numbers. Given the estimated $\pm 1 \mathrm{kcal} \mathrm{mol}^{-1}$ error bar on their experimental $\Delta G(T)$, the agreement with theory is acceptable. The sharp drop in the calculated $\Delta G(T)$ for the reaction $\mathrm{HSO}_{4}{ }^{-}\left(\mathrm{H}_{2} \mathrm{O}\right)_{4}+\mathrm{H}_{2} \mathrm{O} \rightarrow \mathrm{HSO}_{4}{ }^{-}\left(\mathrm{H}_{2} \mathrm{O}\right)_{5}$ marks the biggest disagreement between theory and experiment. The unusual stability of the $\mathrm{HSO}_{4}{ }^{-}\left(\mathrm{H}_{2} \mathrm{O}\right)_{5}$ moiety, however, may not just be an artifact of our methodology. Quadrupole time-offlight mass spectroscopy (QTOF MS) experiments of bisulfate hydrates by Zatula et al. ${ }^{112}$ do show increased intensity for the $\mathrm{HSO}_{4}{ }^{-}\left(\mathrm{H}_{2} \mathrm{O}\right)_{5}$ cluster relative to $\mathrm{HSO}_{4}{ }^{-}\left(\mathrm{H}_{2} \mathrm{O}\right)_{4}$ and $\mathrm{HSO}_{4}{ }^{-}\left(\mathrm{H}_{2} \mathrm{O}\right)_{6}$, suggesting that $n=5$ is a magic number. A few larger clusters like $n=12,14,20,26$, and 28 have also demonstrated unusual stability and abundance. This discrepancy between experiment and the present results implies that additional experiments to refine the thermodynamic free energy values may be warranted.

Froyd and Lovejoy have also derived experimental binding enthalpies $(\Delta H)$ and entropies $(\Delta S)$ from a linear fit of the natural logarithm of $K_{\mathrm{eq}}$ to $1 / T$ according to the linearized van't Hoff equation. However, as explained by Nadykto, ${ }^{49}$ a plot of $\ln$ $K_{\text {eq }}$ versus $1 / T$ often has a nonlinear curvature, introducing large uncertainty in derived experimental enthalpies and entropies. There have been many instances in the literature where direct calorimetric determinations of thermochemical properties differed significantly from those derived using the linear van't Hoff analysis. With this caveat, the experimental and theoretical $\Delta H(298.15 \mathrm{~K})$ and $\Delta G(298.15 \mathrm{~K})$ values are compared in Figure 10. The error bars correspond to the $95 \%$ confidence interval. The trend in the $\Delta G(298.15 \mathrm{~K})$ is very similar to that seen in Figure 11 for $\Delta G(221 \mathrm{~K})$ and $\Delta G(271$ $\mathrm{K})$; the calculated values are higher than the experimental ones by $1-2 \mathrm{kcal} \mathrm{mol}^{-1}$. The $\Delta H(298.15 \mathrm{~K})$ comparison is more erratic and is most likely because of limitations associated with the use of the linear van't Hoff relation to derive experimental $\Delta H$ values.

Some of the disagreement between the current and previous works highlights the difficulty of obtaining accurate thermodynamic quantities for hydrogen-bonded systems from theory or experiment. The reliability of the RRHO framework for thermal corrections of hydrogen-bonded systems is a subject of some debate. Kathmann et al. ${ }^{122}$ have argued that accounting for "(1) local anharmonicity of the vibrations for a given cluster configuration and (2) global anharmonicity resulting from sampling between the large number of configurations available within the relevant volume of configuration space" is necessary to get accurate cluster thermodynamics. While we have not corrected for local anharmonicity, we did take global anharmonicity into account by Boltzmann averaging over many low energy configurations. The overall comparison between theory and experiment is better at low temperatures, such as $T=221 \mathrm{~K}$ and $T=271 \mathrm{~K}$ in Figure 11, than it is for higher temperatures $(T=298.15 \mathrm{~K}$ in Figure 10).
4.5. Abundance of $\left(\mathrm{HSO}_{4}{ }^{-}\right)\left(\mathrm{H}_{2} \mathrm{O}\right)_{n}$. Using the Gibbs free energies of stepwise hydration listed at the bottom of Table 6, it is possible to calculate the equilibrium concentration of the bisulfate hydrates in a closed system under specified conditions. The conditions explored here are $T=216.65,273.15,298.15 \mathrm{~K}$ and relative humidity $(\mathrm{RH})$ of $20 \%, 50 \%$, and $100 \%$, conditions chosen because they are representative of the range encountered in the troposphere. The saturation vapor pressure of water $(\mathrm{RH}=100 \%)$ corresponds to a number concentration of $9.89 \times 10^{14}, 1.62 \times 10^{17}$, and $7.70 \times 10^{17} \mathrm{~cm}^{-3}$ at the three temperatures. ${ }^{1}$ Solving the mass-balance equations under these conditions yields the equilibrium hydrate distributions shown in Figure 12. The most notable result is that the bisulfate ion is almost always hydrated in all of the conditions explored here. The only exception is $T=273.15-298.15 \mathrm{~K}$ and $\mathrm{RH}=20 \%$ where about $3-7 \%$ of the ion is unhydrated $(n=0)$. As expected, the monohydrate $(n=1)$, dihydrate $(n=2)$, and trihydrate $(n=3)$ are more abundant at the low $\mathrm{RH}$ of $20 \%$, but the tetrahydrate $(n=4)$ and pentahydrate $(n=5)$ increase in proportion at higher $\mathrm{RH}$ values. The unusual stability of the pentahydrate (see Figure 9) means it forms in greater numbers than even the tetrahydrate $(n=4)$ especially at higher $\mathrm{RH}$ values. The abundance of the hexahydrate $(n=6)$ is too small to appear in Figure 12.

Our calculated hydration distribution correlates well with ion differential mobility particle sizer (Ion-DMPS) measurements in the boreal forests in Finland. ${ }^{26}$ The Ion-DMPS data showed that neutral and IIN occur simultaneously at all times, but with different fractional contributions from each. IIN is typically higher on warmer, drier, and sunnier days compared to colder and more humid days. The conditions that are most favorable for neutral $\mathrm{H}_{2} \mathrm{SO}_{4}-\mathrm{H}_{2} \mathrm{O}$ nucleation are high $\mathrm{H}_{2} \mathrm{SO}_{4}$ concentrations, low temperatures, and high humidity values. ${ }^{84}$ IIN contributes on days with higher temperature, lower relative humidity, and higher ion concentration (sunnier days). $\mathrm{HSO}_{4}{ }^{-}$ is almost always hydrated under all tropospheric conditions (Figure 12), whereas $\mathrm{H}_{2} \mathrm{SO}_{4}$ is much less so. It should be noted that hydration is not equivalent to nucleation, but there is a clear correlation between the two. In addition, our calculated Gibbs energies assume that these hydrates can be treated as ideal gases, which may not be appropriate for larger ion clusters. ${ }^{123}$

4.6. Atmospheric Implications. Because binary nucleation of sulfuric acid and water alone is not enough to account for observed new particle formation rates in the lower troposphere, IIN and the enhancing effects of ternary species such as ammonia and amines are likely to play a significant role in new particle formation under ambient conditions. Ever since Kim et al. ${ }^{124}$ observed that IIN occurs preferentially on negatively charged particles compared to positive ones, experiments by Froyd and Lovejoy ${ }^{45,125}$ and others, ${ }^{21,23,24}$ as well as theoretical calculations by Kurtén ${ }^{126}$ and Nadykto ${ }^{127}$ have demonstrated that $\mathrm{H}_{2} \mathrm{SO}_{4}$ binds more strongly to $\mathrm{HSO}_{4}{ }^{-}$ than $\mathrm{H}_{3} \mathrm{O}^{+}$or a neutral species like $\mathrm{H}_{2} \mathrm{O}$. Both $\mathrm{HSO}_{4}^{-}$and $\mathrm{H}_{3} \mathrm{O}^{+}$bind water more strongly than $\mathrm{H}_{2} \mathrm{SO}_{4}$ because their charge leads to increased charge-dipole and dipole-dipole interactions. $^{22}$ As a result, ions can act as a more effective nucleation core for condensing gas-phase molecules, thus significantly lowering the nucleation barrier. ${ }^{20,22}$ The formation of ionic $\mathrm{HSO}_{4}{ }^{-}\left(\mathrm{H}_{2} \mathrm{O}\right)_{n}$ is slightly more thermodynamically favorable than that of $\mathrm{H}_{2} \mathrm{SO}_{4}\left(\mathrm{H}_{2} \mathrm{O}\right)_{n}$, as shown in Figure S1, Supporting Information. The RI-MP2/CBS Gibbs free energy for adding water to an existing cluster is an average of $0.5-1$ 
kcal mol ${ }^{-1}$ higher for $\mathrm{H}_{2} \mathrm{SO}_{4}\left(\mathrm{H}_{2} \mathrm{O}\right)_{n}$ than it is for $\mathrm{HSO}_{4}{ }^{-}\left(\mathrm{H}_{2} \mathrm{O}\right)_{n}$, and the standard free energy for adding the sixth water is positive at $298.15 \mathrm{~K}$ and $1 \mathrm{~atm}$ for both systems.

While our $\operatorname{CCSD}(\mathrm{T}) / \mathrm{CBS}$ calculations accurately capture the inherent hydrogen-bonding interactions and our configurational samplings guarantee that we have sampled the most important isomers, the application of ideal gas RRHO Gibbs free energies to nucleation conditions is limited. That is because the ideal gas assumption implies that the nucleating species are spatially distant and noninteracting, whereas the movement of prenucleation clusters is constrained in a spatial area around a nucleation center. ${ }^{9}$ Using the ideal gas RRHO model underestimates the entropy term for prenucleation clusters and often gives Gibbs free energies that are large compared to experiment. It has been difficult to calculate nucleation barriers using ab initio methods coupled with an ideal gas RRHO models because of their large computational cost. That makes other approaches like CNT, monomer density functional theory, dynamical nucleation theory (DNT), and molecular dynamics and Monte Carlo simulations with empirical potentials attractive alternatives. ${ }^{9}$

The limitations of the ideal gas RRHO model notwithstanding, the growth of a binary $\mathrm{HSO}_{4}{ }^{-}-\mathrm{H}_{2} \mathrm{O}$ system to a metastable critical cluster is thermodynamically limited at conditions in the lower troposphere. The bisulfate ion is almost always hydrated under tropospheric conditions, and whatever is unhydrated will likely form a cluster with species like sulfuric acid. ${ }^{128}$ The RI-CC2/aV $(\mathrm{T}+\mathrm{d}) \mathrm{Z}$ calculated binding Gibbs free energy of $\mathrm{HSO}_{4}^{-} \cdot \mathrm{H}_{2} \mathrm{SO}_{4}$ cluster is $-34.10 \mathrm{kcal} \mathrm{mol}^{-1}$ in contrast to $-6.93 \mathrm{kcal} \mathrm{mol}^{-1}$ for $\mathrm{H}_{2} \mathrm{SO}_{4} \cdot \mathrm{H}_{2} \mathrm{SO}_{4}$ and about -5 $\mathrm{kcal} \mathrm{mol}^{-1}$ for $\mathrm{HSO}_{4}^{-} \cdot \mathrm{H}_{2} \mathrm{O}$ at $298 \mathrm{~K}^{12}$ Therefore, the bisulfate should mediate or induce nucleation by forming a thermodynamically favorable $\mathrm{HSO}_{4}{ }^{-} \cdot \mathrm{H}_{2} \mathrm{SO}_{4}$ to which more water or other vapor could bind until it reaches a critical cluster size. ${ }^{129,130}$ The formation of the $\mathrm{HSO}_{4}^{-} \cdot \mathrm{H}_{2} \mathrm{SO}_{4}$ cluster will be kinetically limited because the number concentration of ions in the lower troposphere is very small (typically $10^{2}-10^{3} \mathrm{~cm}^{-3}$ ) compared to that of $\mathrm{H}_{2} \mathrm{SO}_{4}\left(10^{5}-10^{8} \mathrm{~cm}^{-3}\right)$ and $\mathrm{H}_{2} \mathrm{O}\left(10^{14}-\right.$ $\left.10^{17} \mathrm{~cm}^{-3}\right){ }^{22,26,32,33}$ The ion pair concentration ${ }^{131}$ reaches a maximum around $10-20 \mathrm{~km}$ above sea level because of increased exposure to GCRs, and IIN could play a larger role there. ${ }^{132}$ Furthermore, because the preference of $\mathrm{H}_{2} \mathrm{SO}_{4}$ to bind to anions is not limited to $\mathrm{HSO}_{4}{ }^{-}$, it could undergo IIN by binding with other anionic species in the atmosphere. ${ }^{126}$ Several studies have argued that ion-induced nucleation dominates new particle formation, ${ }^{133,134}$ whereas others have claimed that it accounts for less than $15 \%$ of new particle formation. $^{40,42}$

\section{CONCLUSIONS}

We used molecular dynamics sampling along with high-level ab initio methods to locate the most stable hydrates of the bisulfate ion with up to six waters. Our $\operatorname{CCSD}(\mathrm{T})$ corrected complete basis set RI-MP2 binding energies were combined with harmonic thermodynamic corrections to yield the Gibbs free energies of hydration at atmospherically relevant temperatures. The thermodynamic values predict that initial formation of $\mathrm{HSO}_{4}^{-}\left(\mathrm{H}_{2} \mathrm{O}\right)_{n=1-6}$ is more favorable than for neutral $\mathrm{H}_{2} \mathrm{SO}_{4}\left(\mathrm{H}_{2} \mathrm{O}\right)_{n=1-6}$; yet this stabilizing effect of the negative charge quickly diminishes for $n>3$. The formation of $\mathrm{HSO}_{4}{ }^{-}\left(\mathrm{H}_{2} \mathrm{O}\right)_{n=1-5}$ is thermodynamically favorable up to $T=$ $298.15 \mathrm{~K}$ and $\mathrm{HSO}_{4}{ }^{-}\left(\mathrm{H}_{2} \mathrm{O}\right)_{6}$ up to $T=273.15 \mathrm{~K}$. These findings suggest that the $\mathrm{HSO}_{4}{ }^{-}$ion by itself will not nucleate water vapor at ambient conditions significantly better than $\mathrm{H}_{2} \mathrm{SO}_{4}$. However, it does form a strong complex with sulfuric acid, and that should allow it to play a role in ion-induced nucleation.

\section{ASSOCIATED CONTENT}

S Supporting Information

A comparison of the RI-MP2/CBS $\mathrm{HSO}_{4}{ }^{-}\left(\mathrm{H}_{2} \mathrm{O}\right)_{n}$ and $\mathrm{H}_{2} \mathrm{SO}_{4}\left(\mathrm{H}_{2} \mathrm{O}\right)_{n}$ stepwise hydration standard free energies, evaluation of many basis set extrapolation schemes, the basis set dependence of the $\operatorname{CCSD}(\mathrm{T})$ correction, RI-MP2/CBS thermodynamic values, and the RI-MP2/aVDZ optimized coordinates. This material is available free of charge via the Internet at http://pubs.acs.org.

\section{AUTHOR INFORMATION}

\section{Corresponding Author}

*E-mail: george.shields@bucknell.edu.

\section{Notes}

The authors declare no competing financial interest.

\section{ACKNOWLEDGMENTS}

We thank the NSF and Bucknell University for their support of this work. This project was supported in part by NSF grant CHE-0848827, and by NSF grants CHE-0116435, CHE0521063, and CHE-0849677 as part of the MERCURY highperformance computer consortium (http://www. mercuryconsortium.org). This research used the National Science Foundation TeraGrid resources provided by the Texas Advanced Computing Center (TACC) under grant number TG-CHE090095. This research also used resources of the National Energy Research Scientific Computing Center, which is supported by the Office of Science of the U.S. Department of Energy under Contract No. DE-AC0205CH11231. We thank the reviewers for their helpful suggestions.

\section{REFERENCES}

(1) Seinfeld, J. H.; Pandis, S. N. Atmospheric Chemistry and Physics: From Air Pollution to Climate Change, 2nd ed.; John Wiley \& Sons, Inc.: New York, 2006.

(2) Foster, P.; Ramaswamy, V. In Climate Change 2007 The Scientific Basis; Solomon, S., Qin, D., Manning, M., Chen, Z., Marquis, M., Averyt, K. B., Tignor, M., Miller, H. L., Eds.; Cambridge University Press: Cambridge, UK, 2007; pp 131-217.

(3) Stevens, B.; Feingold, G. Nature 2009, 461, 607-613.

(4) Kulmala, M.; Lehtinen, K. E. J.; Laaksonen, A. Atmos. Chem. Phys. 2006, 6, 787-793.

(5) Kulmala, M.; Riipinen, I.; Sipilä, M.; Manninen, H. E.; Petäjä, T.; Junninen, H.; Maso, M. D.; Mordas, G.; Mirme, A.; Vana, M.; et al. Science 2007, 318, 89-92.

(6) Weber, R. J.; Marti, J. J.; McMurry, P. H.; Eisele, F. L.; Tanner, D. J.; Jefferson, A. J. Geophys. Res. 1997, 102, 4375-4385.

(7) Kulmala, M.; Vehkamki, H.; Petäja, T.; Dal Maso, M.; Lauri, A.; Kerminen, V. M.; Birmili, W.; McMurry, P. H. J. Aerosol Sci. 2004, 35, 143-176.

(8) Kuang, C.; McMurry, P. H.; McCormick, A. V.; Eisele, F. L. J. Geophys. Res. 2008, 113, D10209.

(9) Zhang, R.; Khalizov, A.; Wang, L.; Hu, M.; Xu, W. Chem. Rev. 2012, 112, 1957-2011.

(10) Ball, S. M.; Hanson, D. R.; Eisele, F. L.; McMurry, P. H. J. Geophys. Res. 1999, 104, 23709-23718.

(11) Benson, D. R.; Yu, J. H.; Markovich, A.; Lee, S. H. Atmos. Chem. Phys. 2011, 11, 4755-4766. 
(12) Kurtén, T.; Loukonen, V.; Vehkamäki, H.; Kulmala, M. Atmos. Chem. Phys. 2008, 8, 4095-4103.

(13) Loukonen, V.; Kurtén, T.; Ortega, I. K.; Vehkamäki, H.; Pádua, A. A. H.; Sellegri, K.; Kulmala, M. Atmos. Chem. Phys. 2010, 10, 49614974.

(14) Wang, L.; Khalizov, A. F.; Zheng, J.; Xu, W.; Ma, Y.; Lal, V.; Zhang, R. Nature Geosci 2010, 3, 238-242.

(15) Erupe, M. E.; Viggiano, A. A.; Lee, S. H. Atmos. Chem. Phys. 2011, 11, 4767-4775.

(16) DePalma, J. W.; Bzdek, B. R.; Doren, D. J.; Johnston, M. V. J. Phys. Chem. A 2011, 116, 1030-1040.

(17) Zhang, R.; Suh, I.; Zhao, J.; Zhang, D.; Fortner, E. C.; Tie, X.; Molina, L. T.; Molina, M. J. Science 2004, 304, 1487-1490.

(18) Zhang, R.; Wang, L.; Khalizov, A. F.; Zhao, J.; Zheng, J.; McGraw, R. L.; Molina, L. T. Proc. Natl. Acad. Sci. U.S.A. 2009, 106, 17650-17654.

(19) Metzger, A.; Verheggen, B.; Dommen, J.; Duplissy, J.; Prevot, A. S. H.; Weingartner, E.; Riipinen, I.; Kulmala, M.; Spracklen, D. V.; Carslaw, K. S.; et al. Proc. Natl. Acad. Sci. U.S.A. 2010, 107, 66466651.

(20) Yu, F.; Turco, R. P. Geophys. Res. Lett. 2000, 27, 883-886.

(21) Wilhelm, S.; Eichkorn, S.; Wiedner, D.; Pirjola, L.; Arnold, F. Atmos. Environ. 2004, 38, 1735-1744.

(22) Curtius, J.; Lovejoy, E. R.; Froyd, K. D. Space Sci. Rev. 2006, $125,159-167$.

(23) Sorokin, A.; Arnold, F.; Wiedner, D. Atmos. Environ. 2006, 40, $2030-2045$.

(24) Sorokin, A.; Arnold, F. Atmos. Environ. 2007, 41, 3740-3747.

(25) Enghoff, M. B.; Svensmark, H. Atmos. Chem. Phys. 2008, 8, 4911-4923.

(26) Gagne, S.; Nieminen, T.; Kurtén, T.; Manninen, H. E.; Petäjä, T.; Laakso, L.; Kerminen, V. M.; Boy, M.; Kulmala, M. Atmos. Chem. Phys. 2010, 10, 3743-3757.

(27) Kulmala, M.; Kerminen, V.-M. Atmos. Res. 2008, 90, 132-150.

(28) Curtius, J. EPJ Web Conf. 2009, 1, 199-209.

(29) Svensmark, H.; Friis-Christensen, E. J. Atmos. Sol.-Terr. Phys. 1997, 59, 1225-1232.

(30) Kirkby, J.; Curtius, J.; Almeida, J.; Dunne, E.; Duplissy, J.; Ehrhart, S.; Franchin, A.; Gagne, S.; Ickes, L.; Kurten, A.; et al. Nature 2011, 476, 429-433.

(31) Carslaw, K. S.; Harrison, R. G.; Kirkby, J. Science 2002, 298, $1732-1737$.

(32) Eisele, F. L.; Lovejoy, E. R.; Kosciuch, E.; Moore, K. F.; Mauldin, R. L., III; Smith, J. N.; McMurry, P. H.; Iida, K. J. Geophys. Res. 2006, 111, D04305.

(33) Kerminen, V. M.; Petäjä, T.; Manninen, H. E.; Paasonen, P.; Nieminen, T.; Sipilä, M.; Junninen, H.; Ehn, M.; Gagné, S.; Laakso, L.; et al. Atmos. Chem. Phys. Discuss. 2010, 10, 16497-16549.

(34) Yu, F.; Turco, R. P. J. Geophys. Res. 2001, 106, 4797-4814.

(35) Yu, F.; Turco, R. P. Atmos. Chem. Phys. 2008, 8, 6085-6102.

(36) Yu, F. J. Geophys. Res. 2010, 115, D03206.

(37) Pierce, J. R.; Adams, P. J. Geophys. Res. Lett. 2009, 36, L09820.

(38) Kulmala, M.; Riipinen, I.; Nieminen, T.; Hulkkonen, M.; Sogacheva, L.; Manninen, H. E.; Paasonen, P.; Petäjä, T.; Dal Maso, M.; Aalto, P. P.; et al. Atmos. Chem. Phys. 2010, 10, 1885-1898.

(39) Lovejoy, E. R.; Curtius, J.; Froyd, K. D. J. Geophys. Res. 2004, 109, D08204.

(40) Iida, K.; Stolzenburg, M.; McMurry, P.; Dunn, M. J.; Smith, J. N.; Eisele, F.; Keady, P. J. Geophys. Res. 2006, 111, D23201.

(41) Boy, M.; Karl, T.; Turnipseed, A.; Mauldin, R. L.; Kosciuch, E.; Greenberg, J.; Rathbone, J.; Smith, J.; Held, A.; Barsanti, K.; et al. Atmos. Chem. Phys. 2008, 8, 1577-1590.

(42) Manninen, H. E.; Nieminen, T.; Riipinen, I.; Yli-Juuti, T.; Gagné, S.; Asmi, E.; Aalto, P. P.; Petäjä, T.; Kerminen, V. M.; Kulmala, M. Atmos. Chem. Phys. 2009, 9, 4077-4089.

(43) Pierce, J. Nat. Geosci. 2011, 4, 665-666.

(44) Eisele, F. L.; Tanner, D. J. J. Geophys. Res. 1993, 98, 9001-9010.

(45) Froyd, K. D.; Lovejoy, E. R. J. Phys. Chem. A 2003, 107, 98129824.
(46) Nadykto, A. B.; Yu, F.; Herb, J. Int. J. Mol. Sci. 2008, 9, 21842193.

(47) Kurtén, T.; Noppel, M.; Vehkamäki, H.; Salonen, M.; Kulmala, M. Boreal Environ. Res. 2007, 12, 431-453.

(48) Blades, A. T.; Klassen, J. S.; Kebarle, P. J. Am. Chem. Soc. 1995, 117, 10563-10571.

(49) Nadykto, A. B.; Yu, F.; Herb, J. Chem. Phys. 2009, 360, 67-73.

(50) Burdick, G. W.; Shields, G. C.; Appling, J. A.; Moran, T. F. Int. J. Mass Spectrom. Ion Processes 1985, 64, 315-333.

(51) Shields, G. C.; Moran, T. F. J. Phys. Chem. 1985, 89, 40274031.

(52) Shields, G. C.; Moran, T. F. Theor. Chim. Acta 1986, 69, 147159.

(53) Shields, G. C.; Wennberg, L.; Wilcox, J. B.; Moran, T. F. Org. Mass Spectrom. 1986, 21, 137-149.

(54) Shields, G. C.; Steiner, P. A.; Nelson, P. R.; Trauner, M. C.; Moran, T. F. Org. Mass Spectrom. 1987, 22, 64-69.

(55) Jurema, M. W.; Shields, G. C. J. Comput. Chem. 1993, 14, 89104.

(56) Kirschner, K. N.; Shields, G. C. Int. J. Quantum Chem. 1994, 349-360.

(57) Lively, T. N.; Jurema, M. W.; Shields, G. C. Int. J. Quantum Chem. 1994, 95-107.

(58) Kirschner, K. N.; Sherer, E. C.; Shields, G. C. J. Phys. Chem. 1996, 100, 3293-3298.

(59) Shields, G. C.; Laughton, C. A.; Orozco, M. J. Am. Chem. Soc. 1997, 119, 7463-7469.

(60) Shields, G. C.; Laughton, C. A.; Orozco, M. J. Am. Chem. Soc. 1998, 120, 5895-5904.

(61) Sherer, E. C.; Bono, S. J.; Shields, G. C. J. Phys. Chem. B 2001, $105,8445-8451$.

(62) Kirschner, K. N.; Lexa, K. W.; Salisburg, A. M.; Alser, K. A.; Joseph, L.; Andersen, T. T.; Bennett, J. A.; Jacobson, H. I.; Shields, G. C. J. Am. Chem. Soc. 2007, 129, 6263-6268.

(63) Lexa, K. W.; Alser, K. A.; Salisburg, A. M.; Ellens, D. J.; Hernandez, L.; Bono, S. J.; Michael, H. C.; Derby, J. R.; Skiba, J. G.; Feldgus, S.; et al. Int. J. Quantum Chem. 2007, 107, 3001-3012.

(64) Salisburg, A. M.; Deline, A. L.; Lexa, K. W.; Shields, G. C.; Kirschner, K. N. J. Comput. Chem. 2009, 30, 910-921.

(65) Jurema, M. W.; Kirschner, K. N.; Shields, G. C. J. Comput. Chem. 1993, 14, 1326-1332.

(66) Dunn, M. E.; Pokon, E. K.; Shields, G. C. J. Am. Chem. Soc. 2004, 126, 2647-2653.

(67) Dunn, M. E.; Pokon, E. K.; Shields, G. C. Int. J. Quantum Chem. 2004, 100, 1065-1070.

(68) Day, M. B.; Kirschner, K. N.; Shields, G. C. Int. J. Quantum Chem. 2005, 102, 565-572.

(69) Day, M. B.; Kirschner, K. N.; Shields, G. C. J. Phys. Chem. A 2005, 109, 6773-6778.

(70) Shields, G. C.; Kirschner, K. N. Synth. React. Inorg. Met.-Org. Chem. 2008, 38, 32-36.

(71) Shields, R. M.; Temelso, B.; Archer, K. A.; Morrell, T. E.; Shields, G. C. J. Phys. Chem. A 2010, 114, 11725-11737.

(72) Temelso, B.; Archer, K. A.; Shields, G. C. J. Phys. Chem. A 2011, $115,12034-12046$.

(73) Temelso, B.; Shields, G. C. J. Chem. Theory Comput. 2011, 7, 2804-2817.

(74) Pickard, F. C.; Dunn, M. E.; Shields, G. C. J. Phys. Chem. A 2005, 109, 4905-4910.

(75) Pickard, F. C.; Pokon, E. K.; Liptak, M. D.; Shields, G. C. J. Chem. Phys. 2005, 122.

(76) Allodi, M. A.; Dunn, M. E.; Livada, J.; Kirschner, K. N.; Shields, G. C. J. Phys. Chem. A 2006, 110, 13283-13289.

(77) Alongi, K. S.; Dibble, T. S.; Shields, G. C.; Kirschner, K. N. J. Phys. Chem. A 2006, 110, 3686-3691.

(78) Dunn, M. E.; Evans, T. M.; Kirschner, K. N.; Shields, G. C. J. Phys. Chem. A 2006, 110, 303-309.

(79) Kirschner, K. N.; Hartt, G. M.; Evans, T. M.; Shields, G. C. J. Chem. Phys. 2007, 126. 
(80) Allodi, M. A.; Kirschner, K. N.; Shields, G. C. J. Phys. Chem. A 2008, 112, 7064-7071.

(81) Dunn, M. E.; Shields, G. C.; Takahashi, K.; Skodje, R. T.; Vaida, V. J. Phys. Chem. A 2008, 112, 10226-10235.

(82) Hartt, G. M.; Shields, G. C.; Kirschner, K. N. J. Phys. Chem. A 2008, 112, 4490-4495.

(83) Morrell, T. E.; Shields, G. C. J. Phys. Chem. A 2010, 114, 42664271.

(84) Temelso, B.; Morrell, T. E.; Shields, R. M.; Allodi, M. A.; Wood, E. K.; Kirschner, K. N.; Castonguay, T. C.; Archer, K. A.; Shields, G. C. J. Phys. Chem. A 2012, 116, 2209-2224.

(85) Pérez, C.; Muckle, M. T.; Zaleski, D. P.; Seifert, N. A.; Temelso, B.; Shields, G. C.; Kisiel, Z.; Pate, B. H. Science 2012, 336, 897-901.

(86) Case, D. A.; Cheatham, T. E.; Darden, T.; Gohlke, H.; Luo, R.; Merz, K. M.; Onufriev, A.; Simmerling, C.; Wang, B.; Woods, R. J. J. Comput. Chem. 2005, 26, 1668-1688.

(87) Neese, F. ORCA 2.8.0; 2011.

(88) Feyereisen, M.; Fitzgerald, G.; Komornicki, A. Chem. Phys. Lett.

1993, 208, 359-363.

(89) Bernholdt, D. E.; Harrison, R. J. Chem. Phys. Lett. 1996, 250, 477-484.

(90) Dunning, T. J. Chem. Phys. 1989, 90, 1007-1023.

(91) Kendall, R.; Dunning, T.; Harrison, R. J. Chem. Phys. 1992, 96, 6796-6806.

(92) Woon, D.; Dunning, T. J. Chem. Phys. 1993, 98, 1358-1371.

(93) Weigend, F.; Kohn, A.; Hattig, C. J. Chem. Phys. 2002, 116, $3175-3183$

(94) Weigend, F.; Haser, M. Theor. Chem. Acc. 1997, 97, 331-340.

(95) Dunning, T. H.; Peterson, K. A.; Wilson, A. K. J. Chem. Phys. 2001, 114, 9244-9253.

(96) Cramer, C. Essentials of Computational Chemistry: Theories and Models; Wiley: New York, 2004.

(97) Klopper, W.; Bak, K. L.; Jorgensen, P.; Olsen, J.; Helgaker, T. J. Phys. B: At., Mol. Opt. Phys. 1999, 32, R103-R130.

(98) Boys, S. F.; Bernardi, F. Mol. Phys. 1970, 19, 533-566.

(99) Klopper, W. J. Chem. Phys. 1995, 102, 6168-6179.

(100) Xantheas, S. S. J. Chem. Phys. 1996, 104, 8821-8824.

(101) Halkier, A.; Helgaker, T.; Jorgensen, P.; Klopper, W.; Koch, H.; Olsen, J.; Wilson, A. K. Chem. Phys. Lett. 1998, 286, 243-252.

(102) Halkier, A.; Helgaker, T.; Jorgensen, P.; Klopper, W.; Olsen, J. Chem. Phys. Lett. 1999, 302, 437-446.

(103) Klopper, W.; Manby, F. R.; Ten-No, S.; Valeev, E. F. Int. Rev. Phys. Chem. 2006, 25, 427-468.

(104) Lane, J. R.; Kjaergaard, H. G. J. Chem. Phys. 2009, 131, 034307. (105) Bischoff, F. A.; Wolfsegger, S.; Tew, D. P.; Klopper, W. Mol. Phys. 2009, 107, 963-975.

(106) Werner, H. J.; Adler, T. B.; Manby, F. R. J. Chem. Phys. 2007, $126,164102$.

(107) Werner, H.-J.; Knowles, P. J.; Knizia, G.; Manby, F. R.; Schütz, M.; Celani, P.; Korona, T.; Lindh, R.; Mitrushenkov, A.; Rauhut, G.; Shamasundar, K. R.; Adler, T. B.; Amos, R. D.; Bernhardsson, A.; Berning, A.; Cooper, D. L.; Deegan, M. J. O.; Dobbyn, A. J.; Eckert, F.; Goll, E.; Hampel, C.; Hesselmann, A.; Hetzer, G.; Hrenar, T.; Jansen, G.; Köppl, C.; Liu, Y.; Lloyd, A. W.; Mata, R. A.; May, A. J.; McNicholas, S. J.; Meyer, W.; Mura, M. E.; Nicklaß, A.; O'Neill, D. P.; Palmieri, P.; Pflüger, K.; Pitzer, R.; Reiher, M.; Shiozaki, T.; Stoll, H.; Stone, A. J.; Tarroni, R.; Thorsteinsson, T.; Wang, M.; Wolf, A. MOLPRO: a Package of Ab Initio Programs; University College Cardiff Consultants Limited: Cardiffm, UK, 2010.

(108) Peterson, K. A.; Adler, T. B.; Werner, H. J. Chem. Phys. 2008, $128,084102$.

(109) Marshall, M. S.; Burns, L. A.; Sherrill, C. D. J. Chem. Phys. 2011, 135, 194102.

(110) Carrell, E. J.; Thorne, C. M.; Tschumper, G. S. J. Chem. Phys. 2012, 136, 014103-014111.

(111) Nauta, K.; Miller, R. E. Science 2000, 287, 293-295.

(112) Zatula, A. S.; Andersson, P. U.; Ryding, M. J.; Uggerud, E. Phys.

Chem. Chem. Phys. 2011, 13, 13287-13294.
(113) Min, S. K.; Lee, E. C.; Lee, H. M.; Kim, D. Y.; Kim, D.; Kim, K. S. J. Comput. Chem. 2008, 29, 1208-1221.

(114) Bates, D. M.; Tschumper, G. S. J. Phys. Chem. A 2009, 113, 3555-3559.

(115) Yacovitch, T. I.; Wende, T.; Jiang, L.; Heine, N.; Meijer, G.; Neumark, D. M.; Asmis, K. R. J. Phys. Chem. Lett. 2011, 2, 2135-2140.

(116) Vchirawongkwin, V.; Kritayakornupong, C.; Rode, B. M. J. Phys. Chem. B 2010, 114, 11561-11569.

(117) Zhou, J.; Santambrogio, G.; Brummer, M.; Moore, D.; Woste, L.; Meijer, G.; Neumark, D.; Asmis, K. J. Chem. Phys. 2006, 125, 111102 .

(118) Sugawara, S.; Yoshikawa, T.; Takayanagi, T.; Shiga, M.; Tachikawa, M. J. Phys. Chem. A 2011, 115, 11486-11494.

(119) Grimme, S. J. Comput. Chem. 2004, 25, 1463-1473.

(120) Santra, B.; Michaelides, A.; Scheffler, M. J. Chem. Phys. 2007, $127,184104$.

(121) Holland, P. M.; Castleman, A. W. J. Phys. Chem. 1982, 86, 4181-4188.

(122) Kathmann, S.; Schenter, G.; Garrett, B. J. Phys. Chem. C 2007, $111,4977-4983$.

(123) Zhao, J.; Khalizov, A.; Zhang, R. Y.; McGraw, R. J. Phys. Chem. A 2009, 113, 680-689.

(124) Kim, T. O.; Adachi, M.; Okuyama, K.; Seinfeld, J. H. Aerosol Sci. Technol. 1997, 26, 527-543.

(125) Froyd, K. D.; Lovejoy, E. R. J. Phys. Chem. A 2003, 107, 98009811.

(126) Kurtén, T.; Ortega, I. K.; Vehkamäki, H. J. Mol. Struct. (THEOCHEM) 2009, 901, 169-173.

(127) Nadykto, A. B.; Yu, F. Q.; Herb, J. Phys. Chem. Chem. Phys. 2008, 10, 7073-7078.

(128) Lovejoy, E. R.; Curtius, J. J. Phys. Chem. A 2001, 105, 1087410883.

(129) Hanson, D. R.; Lovejoy, E. J. Phys. Chem. A 2006, 110, 95259528.

(130) Petäjä, T.; Sipilä, M.; Paasonen, P.; Nieminen, T.; Kurtén, T.; Ortega, I. K.; Stratmann, F.; Vehkamäki, H.; Berndt, T.; Kulmala, M. Phys. Rev. Lett. 2011, 106, 228302.

(131) Rosen, J. M.; Hofmann, D. J.; Gringel, W. J. Geophys. Res. 1985, 90, 5876-5884.

(132) Stozhkov, Y. I. J. Phys. G: Nucl. Part. Phys. 2003, 29, 913.

(133) Yu, F.; Turco, R. Atmos. Chem. Phys. 2008, 8, 6085-6102.

(134) Kazil, J.; Lovejoy, E. R.; Barth, M. C.; O’Brien, K. Atmos. Chem. Phys. 2006, 6, 4905-4924. 